\section{(อ)} OPEN ACCESS

\title{
Efficacy of pharmacological treatment in rheumatoid arthritis: a systematic literature research informing the 2019 update of the EULAR recommendations for management of rheumatoid arthritis
}

\author{
Andreas Kerschbaumer 다, ${ }^{1}$ Alexandre Sepriano 주, 2,3 Josef S Smolen, ${ }^{1}$ \\ Désirée van der Heijde (1), ${ }^{2}$ Maxime Dougados, ${ }^{4}$ Ronald van Vollenhoven, ${ }^{5}$ \\ lain B McInnes, ${ }^{6}$ Johannes W J Bijlsma, ${ }^{7}$ Gerd R Burmester, ${ }^{8}$ Maarten de Wit (i), \\ Louise Falzon, ${ }^{10}$ Robert Landewé ${ }^{5}$
} Handling editor Dimitrios T
Boumpas

- Additional material is published online only. To view please visit the journal online (http://dx.doi.org/10.1136/ annrheumdis-2019-216656)

For numbered affiliations see end of article.

\section{Correspondence to} Dr Andreas Kerschbaumer, Division of Rheumatology, Department of Medicine 3 Medical University of Vienna, Vienna, Austria; andreas.kerschbaumer@ meduniwien.ac.at

Received 17 November 2019 Revised 7 January 2020 Accepted 8 January 2020 Published Online First 7 February 2020

\section{GLinked}

- http://dx.doi.org/10.1136/ annrheumdis-2019-216653

- http://dx.doi.org/10.1136/ annrheumdis-2019-216655

- http://dx.doi.org/10.1136/ annrheumdis-2019-216821

Check for updates

(C) Author(s) (or their employer(s)) 2020. Re-use permitted under CC BY-NC. No commercial re-use. See rights and permissions. Published by BMJ.

To cite: Kerschbaumer $A$ Sepriano A, Smolen JS, et al. Ann Rheum Dis 2020:79:744-759.

\section{ABSTRACT}

Objectives To inform the 2019 update of the European League against Rheumatism (EULAR) recommendations for the management of rheumatoid arthritis (RA)

Methods A systematic literature research (SLR) to investigate the efficacy of any disease-modifying antirheumatic drug (DMARD) (conventional synthetic (cs)DMARD, biological (b) and biosimilar DMARD, targeted synthetic (ts)DMARD) or glucocorticoid (GC) therapy in patients with RA was done by searching MEDLINE, Embase and the Cochrane Library for articles published between 2016 and 8 March 2019.

Results 234 abstracts were selected for detailed assessment, with 136 finally included. They comprised the efficacy of bDMARDs versus placebo or other bDMARDs, efficacy of Janus kinase (JAK) inhibitors (JAKi) across different patient populations and head-to-head of different bDMARDs versus JAKi or other bDMARDs. Switching of bDMARDs to other bDMARDs or tsDMARDs, strategic trials and tapering studies of bDMARDs, csDMARDs and JAKi were assessed. The drugs evaluated included abatacept, adalimumab, ABT-122, baricitinib, certolizumab pegol, SBI-087, CNT06785, decernotinib, etanercept, filgotinib, golimumab, GCs, GS-9876, guselkumab, hydroxychloroquine, infliximab, leflunomide, mavrilimumab, methotrexate, olokizumab, otilimab, peficitinib, rituximab, sarilumab, salazopyrine, secukinumab, sirukumab, tacrolimus, tocilizumab, tofacitinib, tregalizumab, upadacitinib, ustekinumab and vobarilizumab. The efficacy of many bDMARDs and tsDMARDs was shown. Switching to another tumour necrosis factor inhibitor (TNFi) or non-TNFi bDMARDs after TNFi treatment failure is efficacious. Tapering of DMARDs is possible in patients achieving long-standing stringent clinical remission; in patients with residual disease activity (including patients in LDA) the risk of flares is increased during the tapering. Biosimilars are non-inferior to their reference products.

Conclusion This SLR informed the task force regarding the evidence base of various therapeutic regimen for the development of the update of EULAR's RA management recommendation.

\section{Key messages}

What is already known about this subject?

- Since the 2016 update of the recommendations for the management of rheumatoid arthritis (RA), the body of evidence has grown vividly. Therefore, this systematic literature research (SLR) was performed to inform the 2019 European League against Rheumatism (EULAR) task force with the summarised evidence on efficacy of conventional and targeted synthetic disease-modifying antirheumatic drugs (DMARDs), biological DMARDs and glucocorticoids.

What does this study add?

- Trials comparing biological DMARDs have shown similar efficacy, regardless of the underlying mode of action.

- Head-to-head trials between Janus kinase (JAK) inhibitors (JAKi) and tumour necrosis factor inhibitor inhibitors did not reveal clinically important differences in efficacy.

- Drug tapering of DMARDs, including JAKi is possible, especially in patients achieving stable remission.

- Treating patients to target using MRI-defined remission does not lead to better outcomes when compared with a conventional clinical treat-to-target strategy.

How might this impact on clinical practice or future developments?

- This SLR, alongside with the safety SLR, provided the 2019 EULAR RA management recommendations task force with the emerged evidence since 2016.

\section{INTRODUCTION}

To provide the task force on the 2019 update of the European League against Rheumatism (EULAR) recommendations for the pharmacological management of rheumatoid arthritis (RA) with all available evidence that had emerged since the last update, systematic literature researches (SLRs) 
were performed. In 2016, three SLRs were conducted assessing efficacy of biological disease-modifying antirheumatic drugs (bDMARDs), ${ }^{1}$ efficacy of glucocorticoids (GCs), conventional synthetic (cs) and targeted synthetic (ts) DMARDs, ${ }^{2}$ and safety of pharmacological treatments in RA. ${ }^{3}$ The 2019 update was based on two SLRs, one on safety and the present one on efficacy of pharmacological interventions in RA.

The body of evidence has grown vividly in the last 3 years, especially regarding tsDMARDs inhibiting Janus Kinase inhibitor (JAKi), novel bDMARDs targeting new as well as established pathways and trials comparing bDMARDs to other bDMARDs or tsDMARDs, providing important information on the comparative efficacy of these compounds. ${ }^{4}$ Further, studies on tapering and stopping treatment broaden the information base for rheumatologists and patients on the question of possible disease flares after tapering or cessation of drugs, once patients have reached the clinical target. Strategic studies on how to optimally treat patients to target, ${ }^{5}$ using clinical and imaging targets have also answered important research questions. ${ }^{6}$ Finally, a large number of trials compared the efficacy and safety of biosimilars (bs) DMARDs with those of their bio-originators (bo), including switching between boDMARD and respective bsDMARDs.

This SLR was conducted to update the evidence on efficacy of pharmacological interventions in RA. This involves the evidence accrued since the last update of the treatment recommendations for RA, published by EULAR in 2016. ${ }^{7}$ Another SLR focusing on safety of pharmacological treatments in RA is published separately. ${ }^{8}$

\section{METHODS}

The EULAR updated standard operating procedures were followed, ${ }^{9}$ and an SLR protocol was developed and approved by the steering committee.

Studies eligible for inclusion in this SLR were randomised, controlled, double-blind trials investigating csDMARDs, bDMARDs (bo and bsDMARDs), tsDMARDs or GCs in adult patients with RA classified according to the 2010 American College of Rheumatology (ACR)/EULAR or the ACR 1987 criteria. This SLR was considered to further update the available evidence since the previous SLRs, therefore, articles published between 1 January 2016 and 8 March 2019 with no language restriction were searched. Additionally, studies presented as conference abstracts at the EULAR and ACR annual meetings from 2016 to 2018 were also eligible for inclusion. References of original articles published on submission of the manuscript (after the data cut), but with respective conference abstracts included before, were included in the reference list.

The initial literature search was conducted by an experienced librarian (LF) using Medline, Embase, The Cochrane CENTRAL Register of Controlled Trials (Central) and the EULAR/ACR abstract archives as information sources. The detailed search strategy for each database is shown in the online supplementary tables S1.1-S1.6.

The study selection process was conducted independently by two investigators (AK and AS) and discussed until agreement was achieved. A senior methodologist (RL) was consulted in the case of uncertainties. After the initial title and abstract screening for identification of reports of potential interest, a detailed assessment for eligibility of preselected articles was done. Data of eligible studies were extracted based on standardised methods using pivotal forms. Variables of interest were predefined in the review protocol, including signs and symptoms of arthritis and commonly used composite measures, respective core set variables, physical function, patient-reported outcomes and measures of structural damage.

Sixteen research questions were defined according to the Patient population, Intervention, Control, Outcome (PICO) principle with the help of the steering committee. All typical RA study populations were included, methotrexate (MTX)-naïve or generally DMARD-naïve patients, csDMARD insufficient responders (IR), bDMARD-IR or tsDMARD-IR. Adequately defined control groups receiving either placebo or active treatment were mandatory for inclusion in this analysis. These involved the efficacy of bDMARDs with or without csDMARD combination, head-to-head comparisons of bDMARDs and switching between different bDMARDs, tapering and stopping bDMARDs, as well as the efficacy of tsDMARDs and the respective head-to-head comparison to bDMARDs. Other research questions involved biosimilars, switching between bsDMARDs and respective boDMARD, the efficacy of csDMARDs and the efficacy of GC (in combination with csDMARDs). All interventions of interest are shown in online supplementary table S1.7. A detailed description of the PICOs is shown in online supplementary table S1.8.

Risk of bias (RoB) in individual studies was assessed at study level using the Cochrane Collaborations Risk of Bias tool for randomised controlled trials (RCTs). The assessment was done independently by two investigators (AK and AS). Differing assessments were discussed until consensus was reached.

Due to the heterogeneity of the available studies, no metaanalysis was performed, and results will be reported narratively. Descriptive forest plots were created using RevMan V.5.3 (Copenhagen: The Nordic Cochrane Centre, The Cochrane Collaboration, 2014).

\section{RESULTS}

The study selection process involved 15037 references. After deduplication, 7876 remained for title and abstract screening, of which 234 were selected for full article review and 136 articles finally included. A detailed flow chart is depicted in figure 1. Details of all studies included are shown in online supplementary table S2.1.

RoB was considered as low for most RCTs included. RCTs were rated as having an unclear RoB most commonly due to insufficient reporting of random sequence generation and/or allocation concealment. Due to their unblinded nature, open-label studies were considered as having a high RoB. Trials reported in conference abstracts were not assessed regarding RoB due to limited information. Results of the RoB assessment are shown in online supplementary table S2.2.

Characteristics of each trial for which data were extracted (study size, PICOs), baseline characteristics (online supplementary table S2.3-S2.12), results of studies and summary data for each intervention group (online supplementary table S3.1-S3.13) as well as the respective citations (section 4 in the online supplementary appendix) are shown in the supplement. A summary of included trials and therapies investigated is shown in table 1 .

\section{Efficacy of csDMARDs (or combination of csDMARDs) versus other csDMARDs}

Five trials (all with unclear or high RoB) investigated the efficacy of csDMARDs alone or in combination versus other csDMARDs (see table 1). Baseline characteristics and detailed results are shown in online supplementary table S2.12 and online supplementary table S3.13, respectively. 


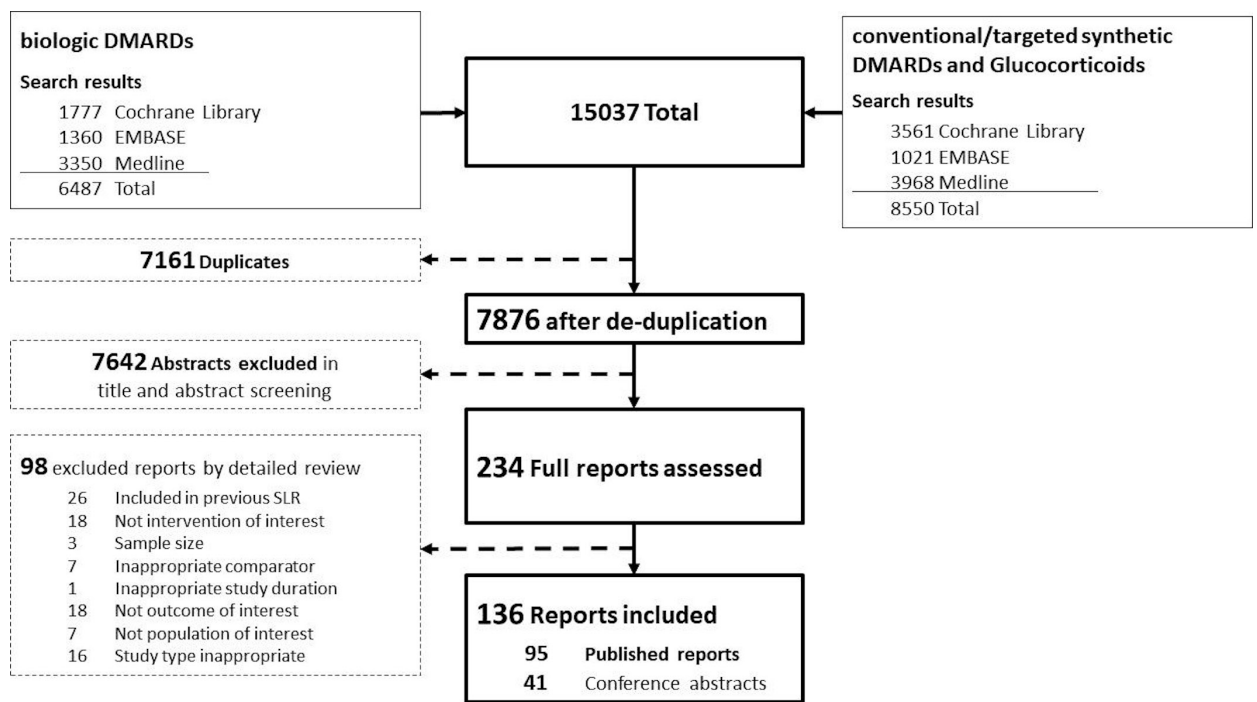

Figure 1 PRISMA flow chart describing the study selection process. DMARDs, disease-modifying antirheumatic drugs; PRISMA, Preferred Reporting Items for Systematic Reviews and Meta-Analyses; SLR, systematic literature research.

The open-label CareRA trial (high RoB) stratified very early, csDMARD naive patients based on their risk factors (presence of erosions, disease activity, rheumatoid factor and anticitrullinated protein antibodies) into high and low risk. ${ }^{10}$ High-risk patients were randomised to three different csDMARD regimens (Combination therapy for early Rheumatoid Arthritis (COBRA) classic: methotrexate (MTX) + sulfasalazine (SSZ) + prednisone $60 \mathrm{mg}$ step-down vs COBRA Slim: MTX+prednisone $30 \mathrm{mg}$ step-down vs COBRA Avant Garde: MTX+leflunomide (LEF) + prednisone $60 \mathrm{mg}$ step-down). Low-risk patients were either randomised to MTX tight-step up or COBRA Slim). The treatment arms investigated in high-risk patients showed comparable efficacy in achieving the primary endpoint (Disease Activity Score of 28 joints (DAS28)-C reactive protein $($ CRP) $<2.6$ ) at week 52 for COBRA Classic (64.3\%, 63/98).

COBRA Slim (60.2\%, 59/98) and COBRA Avant Garde (62.4\%, 58/93, $\mathrm{p}=0.840)$. In low-risk patients, COBRA-Slim and MTX-tight step up also showed comparable efficacy at week $52(67.4 \%, 29 / 43$ vs $57.4 \%, 27 / 47, \mathrm{p}=0.329)$. However, the area under the curves for mean DAS28-CRP change from baseline as well as time-to-remission were favouring MTX plus prednisone combination therapy. Radiographic damage was minimal and comparable across all treatment arms. Sustained and comparable efficacy was shown after 2 years of treatment in high-risk patients. $^{11}$

Investigation of LEF plus SSZ plus hydroxychloroquine (HCQ) triple therapy compared with MTX+SSZ+ HCQ triple therapy or LEF alone in a 48 -week double-blind RCT was terminated early due to gastrointestinal complications in the LEF +SSZ+ HCQ arm. Conventional triple therapy (MTX+SSZ+ HCQ) was superior to LEF +SSZ+ HCQ and LEF alone (ACR20: 87\% vs $46 \%, \mathrm{p}<0.01,87 \%$ vs $36 \%, \mathrm{p}<0.001$, respectively), with no apparent efficacy benefit of the LEF triple therapy compared with LEF alone at week 48 (ACR20: 46\% vs 36\%, p>0.05). ${ }^{12}$

\section{Efficacy of bDMARDs, alone or in combination with csDMARDs, in CSDMARD and bDMARD-IR patients with (established) RA}

Trials comparing bDMARDs to placebo with or without csDMARD background therapy (21 articles/abstracts, 7 with low RoB) showed effective reduction of signs and symptoms for several different modes of action (see table 1), including molecules targeting B-cells (SBI-087, BCD-020), ${ }^{13} 14$ interferon-6 (IL-6) receptor (sarilumab), ${ }^{15}{ }^{16}$ IL-6 cytokine (sirukumab, olokizumab, vobarilizumab), ${ }^{17-22}$ GM-CSF receptor (mavrilimumab) and GM-CSF cytokine (otilimab). ${ }^{23-25}$ IL-12/23 inhibition (ustekinumab) and IL23i (guselkumab) did not show significant differences from placebo. Molecules targeting IL-17A (secukinumab, CNTO6785), ${ }^{26-28}$ and CD4 (tregalizumab) showed no or only minor efficacy compared with placebo (and lower efficacy compared with abatacept (ABA) as active comparator) in different patient populations. ${ }^{29}$ Primary efficacy outcomes are summarised in table 2, baseline characteristics are shown in online supplementary table S2.3 and secondary efficacy outcomes in online supplementary table S3.1.

\section{Trials comparing bsDMARDs to boDMARDs}

Twenty-four non-inferiority trials (12 with low RoB) investigated the bioequivalence of bsDMARDs to their respective boDMARDs. All showed conclusive comparable results, irrespective of the compound (adalimumab (ADA), etanercept, infliximab and rituximab; for bsDMARD studied see table 1, online supplementary table S2.10 and online supplementary table S3.11). . $^{30-55}$

Switching between biosimilars and bio-originators revealed no changes in efficacy in trials of one ADA (SB5, low RoB), ${ }^{56}$ three etanercept (two with low RoB: GP2015, LBEC0101; CHS-0214: conference abstract-RoB not assessed),,$^{32-59}$ and two infliximab biosimilars (SB2, CT-P13, both low RoB). ${ }^{60} 61$ Detailed characteristics and results of the studies are shown in online supplementary tables S2.11 and S3.11.

\section{Head-to-head studies (bDMARDs)}

Seven bDMARD head-to-head studies were included (six with low RoB; one high RoB). Efficacy results are summarised in table 3 (baseline characteristics and detailed efficacy outcomes are shown in online supplementary tables S2.3 and S3.2.).

The Optimal Management of patients with rheumatoid arthritis who Require Biologic Therapy (ORBIT) trial (high RoB), an open-label non-inferiority RCT comparing B-Cell depletion (rituximab) to tumour necrosis factor inhibitor (TNFi) therapy in csDMARD-IR and bDMARD-naïve patients, found 
Table 1 Interventions and therapeutic compounds of trials included for review

\begin{tabular}{|c|c|c|c|}
\hline Intervention & No of articles/ abstracts* & Therapeutic compound & Target \\
\hline \multirow{4}{*}{$\begin{array}{l}\text { csDMARDs, csDMARD combination, } \\
\text { Glucocorticoids versus other csDMARDs } \\
\text { or placebo }\left({ }^{10-12} 130131\right)\end{array}$} & \multirow[t]{4}{*}{5} & $\begin{array}{l}\text { Tacrolimus +methotrexate (MTX) versus } \\
\text { leflunomide+MTX }\end{array}$ & \multirow{4}{*}{$\begin{array}{l}\text { FKBP12; dihydrofolate reductase } \\
\text { +purine metabolism; dihydroorotate } \\
\text { dehydrogenase }\end{array}$} \\
\hline & & $\begin{array}{l}\text { MTX+sulfasalazine + glucocorticoids versus } \\
\text { MTX + glucocorticoids versus MTX + Leflunomide } \\
\text { +Glucocorticoids }\end{array}$ & \\
\hline & & MTX versus MTX+glucocorticoids & \\
\hline & & $\begin{array}{l}\text { MTX+sulfasalazine + Hydroxychloroquine versus } \\
\text { leflunomide +sulfasalazine + hydroxychloroquine } \\
\text { versus leflunomide monotherapy }\end{array}$ & \\
\hline \multirow{11}{*}{$\begin{array}{l}\text { bDMARD } \pm \text { csDMARDs versus placebo } \\
\left({ }^{13-29132-136}\right)\end{array}$} & \multirow[t]{11}{*}{21} & BCD-020 & \multirow[t]{2}{*}{ CD-20 } \\
\hline & & SBI-087 & \\
\hline & & Tregalizumab & CD-4 \\
\hline & & Abatacept & CD-80/CD-86 \\
\hline & & Certolizumab pegol & TNF \\
\hline & & CNT06785 & \multirow[t]{2}{*}{ IL-17 } \\
\hline & & Secukinumab & \\
\hline & & Otilimab & GM-CSF \\
\hline & & Mavrilimumab & GM-CSF receptor \\
\hline & & Ustekinumab & IL-12/23 \\
\hline & & Guselkumab & IL-23 \\
\hline \multirow{4}{*}{$\begin{array}{l}\text { bDMARDs versus other bDMARDs }\left({ }^{462-66}\right. \\
137138)\end{array}$} & \multirow[t]{4}{*}{8} & Rituximab versus etanercept/adalimumab & $\mathrm{CD}-20$ versus TNF \\
\hline & & ABT-122 versus adalimumab & TNF/IL-17A versus TNF \\
\hline & & Certolizumab pegol versus adalimumab & TNF \\
\hline & & Sirukumab versus adalimumab & IL- 6 versus TNF \\
\hline \multirow[t]{3}{*}{ Switching between bDMARDs $\left({ }^{46768}\right)$} & \multirow[t]{3}{*}{3} & Certolizumab pegol versus adalimumab & TNF \\
\hline & & $\begin{array}{l}\text { Abatacept; rituximab; tocilizumab versus adalimumab; } \\
\text { certolizumab; infliximab; golimumab; etanercept }\end{array}$ & $\begin{array}{l}\text { CD-80/CD-86; CD-20; IL-6 receptor } \\
\text { versus TNF }\end{array}$ \\
\hline & & Sarilumab & IL-6 receptor \\
\hline \multirow{5}{*}{$\begin{array}{l}\text { Tapering of bDMARDs/tsDMARDs or } \\
\text { csDMARDs }\left({ }^{107-124126-128140-145}\right)\end{array}$} & \multirow[t]{5}{*}{25} & Abatacept & CD-80/CD-86 \\
\hline & & Tocilizumab & IL-6 receptor \\
\hline & & $\begin{array}{l}\text { Adalimumab; certolizumab pegol; etanercept; } \\
\text { infliximab; }\end{array}$ & TNF \\
\hline & & csDMARDs & \\
\hline & & Glucocorticoids & \\
\hline Strategic studies $\left({ }^{6146}\right)$ & 2 & & \\
\hline \multirow{7}{*}{$\begin{array}{l}\text { tsDMARDs } \pm \text { csDMARDs versus placebo } \\
(73-100125147-152)\end{array}$} & \multirow[t]{7}{*}{32} & Baricitinib & JAK $1 / 2$ \\
\hline & & Decernotinib & JAK 3 \\
\hline & & Filgotinib & JAK 1 \\
\hline & & GS-9876 & SYK \\
\hline & & Peficitinib & JAK 1 \\
\hline & & Tofacitinib & JAK $1 / 3$ \\
\hline & & Upadacitinib & JAK 1 \\
\hline \multirow{3}{*}{$\begin{array}{l}\text { tsDMARDs } \pm \text { csDMARDs versus } \\
\text { bDMARDs } \pm \text { csDMARDs }\left({ }^{101-106}\right)\end{array}$} & \multirow[t]{3}{*}{5} & Baricitinib versus adalimumab & JAK $1 / 2$ versus TNF \\
\hline & & Tofacitinib versus adalimumab & JAK $1 / 3$ versus TNF \\
\hline & & Upadacitinib versus adalimumab & JAK 1 versus TNF \\
\hline
\end{tabular}


Table 1 Continued

\begin{tabular}{|c|c|c|c|}
\hline Intervention & No of articles/ abstracts* & Therapeutic compound & Target \\
\hline \multirow[t]{3}{*}{ bsDMARDs versus boDMARDs $\left({ }^{(30-3436-55}\right)$} & \multirow[t]{3}{*}{24} & $\begin{array}{l}\text { Adalimumab: ABP 501, AdaliRel, BI 695501, CinnoRA, } \\
\text { FKB327, GP2017, PF-06410293, SB5, ZRC } 3197\end{array}$ & TNF \\
\hline & & Etanercept: CHS-0214, GP2015, HD203, LBEC0101 & TNF \\
\hline & & Rituximab: BCD-020, CT-P10, DRL-RI, GP2013 & CD-20 \\
\hline $\begin{array}{l}\text { Switching between bsDMARDs and } \\
\text { boDMARDs }\left({ }^{3235} 56-61153\right)\end{array}$ & 6 & Infliximab: SB2, CT-P13 & TNF \\
\hline
\end{tabular}

*Studies answering multiple research questions account for mismatch between included articles/abstracts and numbers in this table. References of manuscripts published after the SLRs data cut, with the respective conference abstracts included before, are shown, but were not counted.

bDMARD, biological disease-modifying antirheumatic drug; boDMARD, biooriginator disease-modifying antirheumatic drug; bsDMARD, biosimilar disease-modifying antirheumatic drug; CD, cluster of differentiation; csDMARD, conventional synthetic disease-modifying antirheumatic drug; GM-CSF, granulocyte-macrophage colony-stimulating factor; IL, interleukin; JAK, Janus kinase; SYK, spleen tyrosine kinase; TNF, tumour necrosis factor; tsDMARD, targeted synthetic disease-modifying antirheumatic drug.

that RTX is non-inferior to TNFi over 52 weeks regarding clinical efficacy. ${ }^{62}$

Sarilumab monotherapy showed clinical and functional superiority compared with ADA monotherapy in patients who were intolerant or inadequately responding to MTX. ${ }^{63}$

Mavrilimumab (targeting GM-CSFR) was compared with golimumab in a 24-week phase $2 b$ trial of csDMARD and/or TNFi-IR patients and had similar efficacy. ${ }^{64}$

ABT-122, a bispecific dual variable domain immunoglobulin targeting TNF and IL-17A, exhibited similar efficacy rates in the $120 \mathrm{mg}$ arm as ADA in MTX-IR patients over 12 weeks. ${ }^{65}$

The SIRROUND-H study investigated superiority of sirukumab (IL-6i) monotherapy over ADA monotherapy in MTXIR, bDMARD naive patients. The study failed to meet one of its coprimary endpoints with no significant differences in ACR 50\% response rates at week 24; the other primary endpoint (DAS28-ESR mean change from baseline at week 24) was met. ${ }^{66}$

The EXXELERATE study did not show superiority of certolizumab pegol compared with ADA and therefore failed to meet its primary endpoint, showing similar ACR20\% response rates at week $12 .^{4}$

\section{Switching between different bDMARDs}

Three trials on switching between different bDMARDs were included (see online supplementary table S2.4 and online supplementary table S3.3 for details).

EXXELERATE also studied the efficacy of single-blinded switching to a second TNFi (without washout) in patients with primary non-response to either certolizumab pegol or ADA (unclear RoB). Twelve weeks after switching 58\% (ADA to certolizumab pegol) and $62 \%$ (certolizumab pegol to ADA) of patients achieved DAS28-ESR $\leq 3.2$ or a DAS28-ESR reduction of 1.2 or more. ${ }^{4}$

An exploratory analysis of the EXTEND trial, an open-label extension study of the ASCERTAIN trial, investigated patients switched from tocilizumab (TCZ) to sarilumab (conference abstract). After 12 and 24 weeks about one-third of patients non-responders to TCZ achieved clinical response (Clinical Disease Activity Index (CDAI) $\leq 10$; ACR70) after switching to sarilumab. ${ }^{67}$

The open-label ROC trial (high RoB) investigated patients who failed one TNFi therapy, comparing non-TNFi therapies (ABA, RTX, TCZ) to a second TNFi drug. The primary efficacy endpoint, superiority in EULAR good or moderate response at week 24, was met with higher responses in the non-TNFi group
(101/146, 69\%) compared with 52\% in the second TNFi group (OR 2.12; 95\% CI 1.31 to $3.46 ; \mathrm{p}=0.003) .{ }^{68}$ bDMARD therapies in early RA patients.

Five reports on induction therapy with bDMARDs in early disease were included (two with low RoB), baseline characteristics are shown in online supplementary table S2.5 and results in online supplementary table S3.4.

In DMARD naïve patients with poor prognostic factors, CZP in combination with dose optimised MTX (C-EARLY) was shown to be superior to placebo +MTX, with $28.9 \%$ of patients achieving sustained DAS28 $<2.6$ at week 40 and week 52 in the combination arm compared with $15 \%$ of patients in the MTX arm. $^{69}$

In the AVERT-2 study, ABA+MTX did not show superiority to placebo +MTX regarding SDAI remission $(\leq 3.3)$ at week 24 $(21.3 \%$ ABA+MTX vs $16 \%$ placebo + MTX), the primary efficacy endpoint. ${ }^{70}$

DINORA compared infliximab + MTX treatment to MTX or placebo treatment only. INF+MTX showed superiority to placebo only, but not to MTX monotherapy, in achieving sustained remission (no swollen joints, $\leq 2$ tender joints and an acute phase within the normal range) after 1 year (32\% vs $14 \%$ vs $0 \%$ for INF + MTX, MTX and placebo, respectively). ${ }^{71}$

TCZ monotherapy as well as combination therapy of TCZ with MTX was clinically superior to MTX therapy in early RA patients. Inhibition of radiographic damage was found to be significantly greater with $8 \mathrm{mg} / \mathrm{kg}$ TCZ intravenous +MTX than in the MTX monotherapy arm modified total Sharp score ( $\Delta$ mTSS 0.08 vs 1.14 ). TCZ $8 \mathrm{mg} / \mathrm{kg}$ intravenous monotherapy showed less radiographic progression than MTX monotherapy ( $\Delta$ mTSS 0.26 vs 1.14 , p value not reported). ${ }^{72}$

\section{Efficacy of tsDMARDs (JAKi)}

In total, 32 articles/abstracts on tsDMARDs were included (see table 1); 16 trials were regarded as having low RoB. Baseline characteristics and efficacy outcomes are shown in online supplementary tables S2.8 and S3.9, respectively.

Decernotinib (JAK-3i) and peficitinib (non-selective JAKi) were effective as monotherapy and in combination with csDMARDs or MTX in various populations. ${ }^{73-82}$

Filgotinib (JAK-1 selective JAKi) was effective in reducing signs and symptoms of RA as well as improving physical function and patients quality of life in two phase II studies investigating MTX-IR patients in combination with MTX (DARWIN 1) and as monotherapy (DARWIN 2). ${ }^{83}$ 
Table 2 Primary efficacy outcomes of trials comparing biological DMARDs with or without background csDMARD therapy to placebo

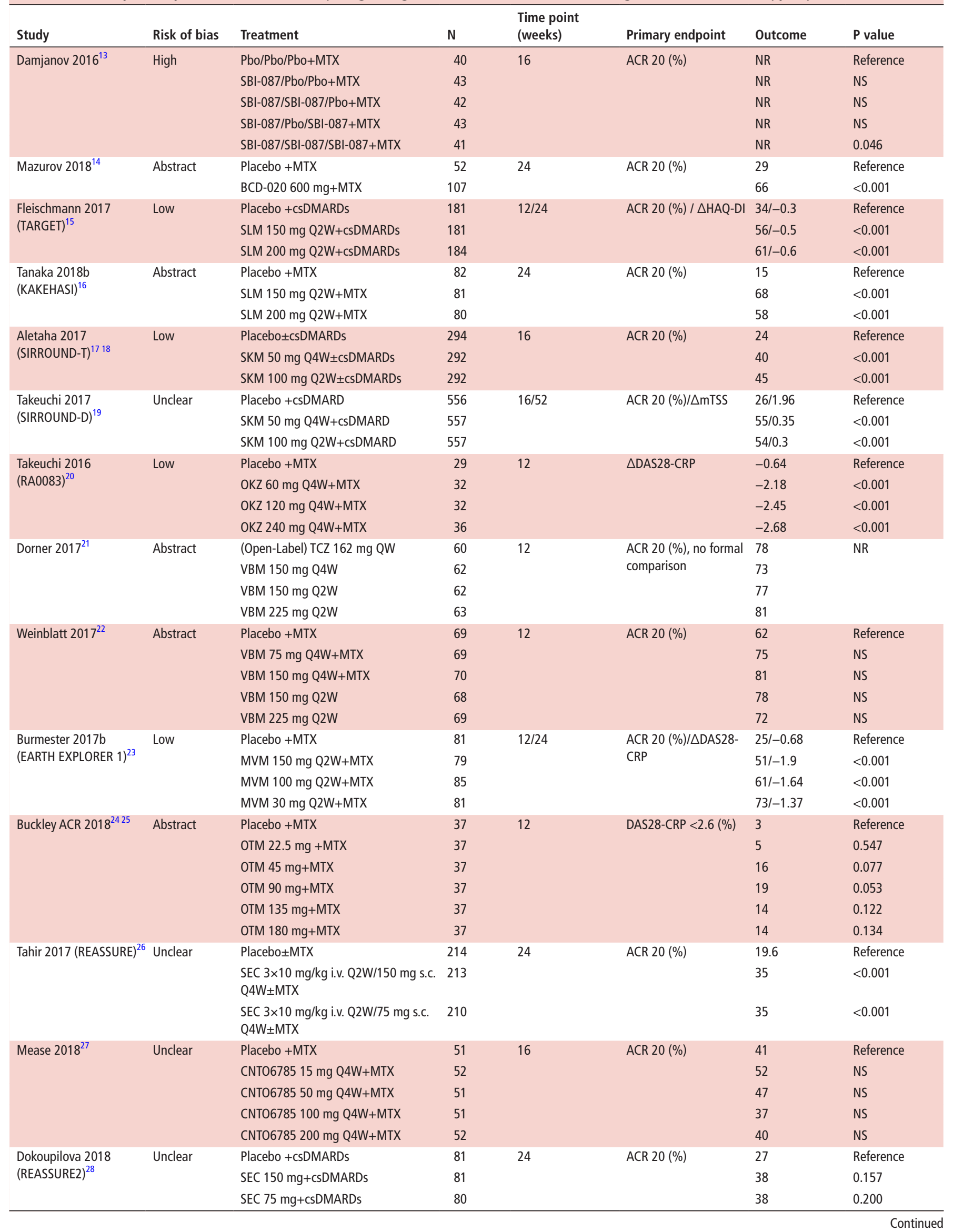




\begin{tabular}{|c|c|c|c|c|c|c|c|}
\hline Study & Risk of bias & Treatment & $\mathrm{N}$ & $\begin{array}{l}\text { Time point } \\
\text { (weeks) }\end{array}$ & Primary endpoint & Outcome & $P$ value \\
\hline \multirow[t]{4}{*}{ van Vollenhoven $2018^{29}$} & Low & Placebo +MTX & 79 & 12 & ACR $20(\%)$ & 35 & Reference \\
\hline & & TLM 25 mg+MTX & 80 & & & 42 & 0.395 \\
\hline & & TLM 100 mg+MTX & 78 & & & 47 & 0.165 \\
\hline & & TLM 200 mg+MTX & 76 & & & 44 & 0.274 \\
\hline \multirow[t]{2}{*}{ Bi 2018 (RAPID-C) $^{132}$} & High & Placebo +MTX & 113 & 24 & ACR $20(\%)$ & 24 & Reference \\
\hline & & $\mathrm{CZP}+\mathrm{MTX}$ & 316 & & & 55 & $<0.001$ \\
\hline \multirow[t]{5}{*}{ Smolen $2017 a^{133}$} & Low & Placebo +MTX & 55 & 28 & ACR 20 (\%) & 40 & Reference \\
\hline & & UKM 90 mg Q8W+MTX & 55 & & & 53 & 0.877 \\
\hline & & UKM 90 mg Q12W+MTX & 55 & & & 55 & \\
\hline & & GKM 50 mg Q8W+MTX & 55 & & & 38 & 0.101 \\
\hline & & GKM 200 mg Q8W+MTX & 54 & & & 44 & \\
\hline
\end{tabular}

Detailed results of risk of bias analyses are shown in online supplementary table $\$ 2.2$ in the supplementary appendix.

$\triangle$, change from baseline; ACR, American College of Rheumatology response criteria; CsDMARD, conventional synthetic disease-modifying antirheumatic drugs; CZP, certolizumab pegol; DAS28-CRP, Disease Activity Score of 28 joints with C-reactive protein; GKM, guselkumab; HAQ-DI, Health Assessment Questionnaire Disability Index; i.v., intravenous; mTSS, modified total Sharp score; MTX, methotrexate; MVM, mavrilimumab; NR, not reported; NS, not significant; OKZ, olokizumab; OTM, Otilimab; Pbo, placebo; s.c., subcutaneous; SEC, secukinumab; SKM, sirukumab; SLM, sarilumab; TCZ, tocilizumab; TLM, tregalizumab; UKM, ustekinumab; VBM, vobarilizumab.

GS-9876, an oral spleen tyrosine kinase inhibitor did not show clinical efficacy compared with placebo. ${ }^{84}$

Baricitinib (BARI) (JAK-1/2i) showed efficacy compared with placebo in csDMARD-IR (RA-BUILD) patients, ${ }^{85} 86$ MTX-IR patients, ${ }^{8788}$ and in early RA as monotherapy or in combination with MTX. 8990

Upadacitinib proved to be efficacious versus placebo in phase 3 trials of various RA populations, MTX-naive, ${ }^{91}$ csDMARD/ MTX-IR, ${ }^{92-98}$ bDMARD-IR (SELECT-BEYOND) ${ }^{99} 100$ and tsDMARD versus bDMARD head-to-head trials.

Five reports on three different head-to-head trials (three with low RoB) comparing tsDMARDs to ADA were included. Baseline characteristics are shown in online supplementary table S2.9 and detailed efficacy results in online supplementary table S3.10.

In RA-BEAM, BARI $4 \mathrm{mg}+\mathrm{MTX}$ was shown to be superior to ADA $40 \mathrm{mg}$ Q2W + MTX clinically (ACR20 at week 12: 70\% vs $61 \%, \mathrm{p}=0.014 ; \Delta \mathrm{DAS} 28$-CRP at week $12:-2.24$ vs -1.95 , $\mathrm{p}<0.001)$ and functionally $(\triangle \mathrm{HAQ}$ at week $12:-0.66 \mathrm{vs}-0.56$, $\mathrm{p} \leq 0.01)$. Regarding structural progression, ADA and BARI were superior compared with placebo (change from baseline in mTSS at week 24: BARI: 0.41 vs ADA: 0.33 vs placebo: 0.9 , p vs placebo <0.001). ${ }^{101} 102$ Regarding core set variables, the differences related to patient reported outcomes and CRP, but not to swollen joint counts (SJCs).

ORAL strategy investigated the non-inferiority of tofacitinib $5 \mathrm{mg}$ two times per day with or without MTX compared with ADA $40 \mathrm{mg}$ Q2W+MTX. Non-inferiority was demonstrated for tofacitinib + MTX versus ADA + MTX (ACR50 at week 24: $46 \%$ vs $44 \%$, difference: $2 \%$; $98.34 \%$ CI $-6 \%$ to $11 \%)$, but not for tofacitinib monotherapy versus ADA + MTX (ACR50 at week $24: 38 \%$ vs $44 \% ;-6 \%(-14 \%-3 \%))$ or versus tofacitinib + MTX (ACR 50 at week 24: 38\% vs 46\%; -8\% (-16\%1\%)). ${ }^{103104}$

Upadacitinib + MTX was shown to be superior to ADA + MTX in SELECT-COMPARE in both coprimary endpoints (ACR20 at week 12: $70.5 \%$ vs $63 \%, \mathrm{p}<0.05$; DAS28-CRP $<2.6$ at week $12: 28.7 \%$ vs $18 \%, \mathrm{p}<0.001)$, with radiographic superiority of upadacitinib +MTX vs placebo + MTX ( $\Delta$ mTSS at week 26: 0.24 vs $0.92, \mathrm{p}<0.001$ ) and numerically similar results between upadacitinib + MTX and ADA + MTX ( $\triangle$ mTSS at week 26: 0.24 vs 0.10$).{ }^{105106}$ Also in this study, the differences related to patient-reported outcomes and CRP, but not to SJCs.
Key outcomes are summarised in table 4. Figure 2 shows descriptive forest plots using ACR 20/50 and 70 response rates. Figure 3 summarises outcomes of trials investigating the efficacy of bDMARDs and tsDMARDs (based on their mode of action) compared with placebo.

\section{Strategy trials}

IMAGINE-RA, a non-blinded strategic trial (high RoB) which enrolled patients with stable, controlled disease activity (DAS28-CRP $\leq 3.2$ and no swollen joints), compared an MRI guided with a purely clinical treat-to-target strategy. The trial did not meet its coprimary endpoints at month 24 , as no differences in DAS28-CRP $<2.6$ rates ( $85 \%$ vs $88 \%$, respectively) or differences in the proportion of patients who had no radiographic progression (66\% vs 62\%) were observed. However, in the MRIT2T group, more patients needed treatment escalation (73\% vs $17 \%$ ) and initiation of bDMARD therapy (46\% vs 2\%) accompanied by higher costs and three times more serious adverse events. $^{6}$

\section{Tapering and stopping therapy}

In total 25 studies (three with low RoB) investigated tapering and/or stopping csDMARD, bDMARD or tsDMARD therapy. Primary results are shown in table 5, baseline characteristics are shown in online supplementary table S2.7 and secondary outcomes are shown in online supplementary tables S3.6, S3.7 and S3.8

\section{Tapering and stopping csDMARDs or GCs}

MUSICA, a double-blind, non-inferiority RCT (low RoB) investigated randomised MTX dosage reduction to $7.5 \mathrm{mg} /$ week compared with continuation of $20 \mathrm{mg} / \mathrm{week}$ in MTX-IR patients with open-label ADA initiation. The mean DAS28-CRP was statistically lower in the standard-dose group (3.75 vs 4.12, $\mathrm{p}=0.014$ ) and non-inferiority of high versus low MTX dosage was therefore not shown ( $\triangle \mathrm{DAS} 28-\mathrm{CRP} 0.37$ (95\% CI 0.07 to 0.66 ) at week 24 ; NI-margin: $15 \%=0.56) .{ }^{107}$ Thus, a mandatory dose reduction from 20 to $7.5 \mathrm{mg}$ MTX weekly seems too low for combination therapy with a TNFi.

A Canadian open-label RCT (high RoB) reported no differences in DAS28-ESR change after patients treated with certolizumab 


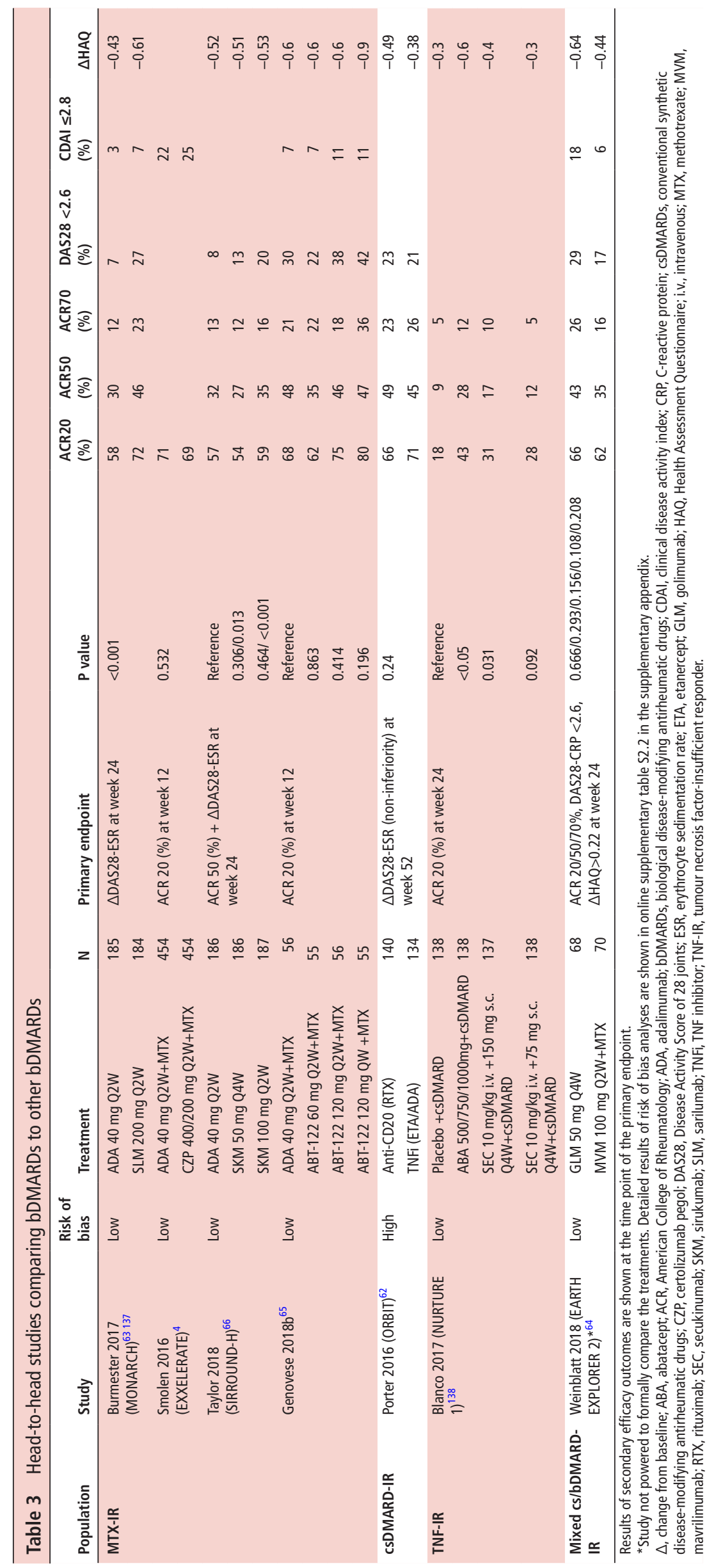




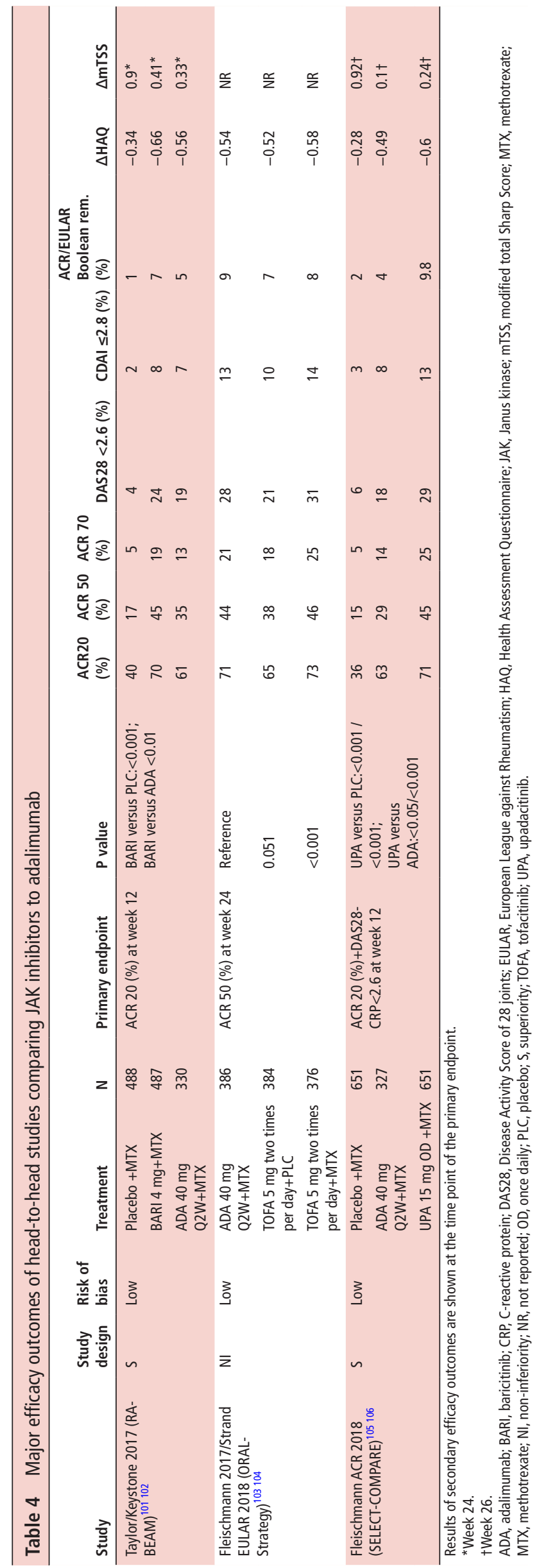

plus csDMARD had been randomised to continue combination therapy or discontinue csDMARDs $(-2.1$ vs -2.1$) .{ }^{108-110}$

The SEMIRA trial (conference abstract) investigated patients treated with TCZ \pm csDMARD therapy who also had stable GC therapy of $5 \mathrm{mg} /$ day, comparing blinded tapering of GCs with continuation of GCs. A significant increase of disease activity ( $\triangle \mathrm{DAS} 28-\mathrm{ESR})$ was seen in the discontinuation group compared with continuation $(0.613,95 \%$ CI 0.346 to $0.879, \mathrm{p}<0.001)$. Sixty-six per cent of patients discontinuing remaining in stable DAS28 $\leq 3.2$ without experiencing disease flares, compared with $77 \%$ (RR $0.833,95 \%$ CI 0.714 to $0.972, \mathrm{p}=0.021$ ) in the stable GC group. ${ }^{111}$

Several trials (one low RoB, one unclear RoB, one high RoB) showed non-inferiority of MTX tapering versus continuation in patients receiving ongoing (long-term) TCZ therapy. ${ }^{112-114}$

A substudy of the CareRA study investigated randomised step-down from COBRA Avant-Garde (MTX+LEF + initial prednisone $30 \mathrm{mg}$ step-down) to either MTX (15 mg/week) or LEF $(20 \mathrm{mg} /$ day $)$ monotherapy if they achieved an DAS28-CRP $\leq 3.2$ after treatment induction during period of $40-52$ weeks of therapy. After 65 weeks, significantly more patients achieved DAS28-CRP $<2.6$, CDAI $\leq 10$ or SDAI $\leq 11$ in the MTX arm $(30 / 32,93.8 \% ; 32 / 32,100 \% ; 32 / 32,100 \%$ respectively) than in the LEF arm $(19 / 26,73.1 \%, \mathrm{p}=0.031 ; 21 / 26,80.8 \%, \mathrm{p}=0.009$; $22 / 26,84.6 \%, \mathrm{p}=0.021)^{115116}$ bDMARD tapering.

The POET study, a large open-label RCT (high RoB) randomised patients in stable low disease activity for 6 months (DAS28-ESR $\leq 3.2$ or based on rheumatologists' impression) to either stop or continue their TNFi therapy, comparing proportions of patients experiencing a disease flare (DAS28-ESR $\geq 3.2$ + DAS28-ESR change from baseline $>0.6$ ) during 12 months. About 20\% of patients could stop their TNFi therapy without experiencing a flare, but among those who continued TNFi therapy $50 \%$ did not experience a flare (TNFi stopping: $18.2 \%$ vs TNFi continuation: $51.2 \%, \mathrm{p}<0.001$; HR $3.50 ; 95 \%$ CI 2.60 to 4.72$).{ }^{117118}$

In C-OPERA, Japanese patients discontinued or continued certolizumab pegol after achieving DAS28-ESR $\leq 3.2$ at week 52. At week 104, 29.3\% of patients who stopped certolizumab pegol could maintain SDAI remission, compared with $41.5 \%$ of patients continuing $(p=0.026)$. Significantly more radiographic progression occurred in patients who stopped certolizumab until week 104 ( $\triangle \mathrm{mTSS}$ at week 1040.66 vs 3.01, $\mathrm{p}=0.001) .{ }^{119}$

In C-EARLY, a trial investigating certolizumab +MTX in csDMARD naive patients with early RA, patients who achieved DAS28-ESR $\leq 3.2$ at year 1 were either continued on CZP every 2 weeks, increased dosing interval of CZP (to every 4 weeks) or stopped CZP completely. Although the trial failed to meet its primary endpoint (\% of patients in DAS28-ESR $\leq 3.2$ without flare at week 104), similar results for CZP Q2W versus interval prolongation to CZP every 4 weeks $(48.8 \%$ vs $53.2 \%, p=0.112)$ were seen. Furthermore, $39.2 \%$ of patients could stop CZP completely and maintain DAS28-ESR $\leq 3.2$ but the difference compared with continuation was significant $(48.8 \%$ vs $39.2 \%$, $\mathrm{p}=0.041) .{ }^{120}$

Further studies investigated the discontinuation of TCZ after combination therapy with MTX (SURPRISE study) and achieving DAS28-ESR <2.6: sustained DAS28-ESR $<2.6$ and DAS28-ESR $\leq 3.2$ rates were more frequent in patients receiving concomitant MTX compared with TCZ monotherapy after 104 weeks ( $24 \%$ vs $14 \%, \mathrm{p}=0.005 ; 55 \%$ vs $27 \%, \mathrm{p}=0.005) .{ }^{121}$ Tapering TNFi dose by $33 \%$ in patients with DAS28-ESR $\leq 3.2$ for 3 months did not lead to increased flare rates $(12 \%$ vs $16 \%$, HR: $0.90,95 \%$ CI 0.23 to $3.48, p=0.873$ ), reducing the TNFi 
ACR20 Response

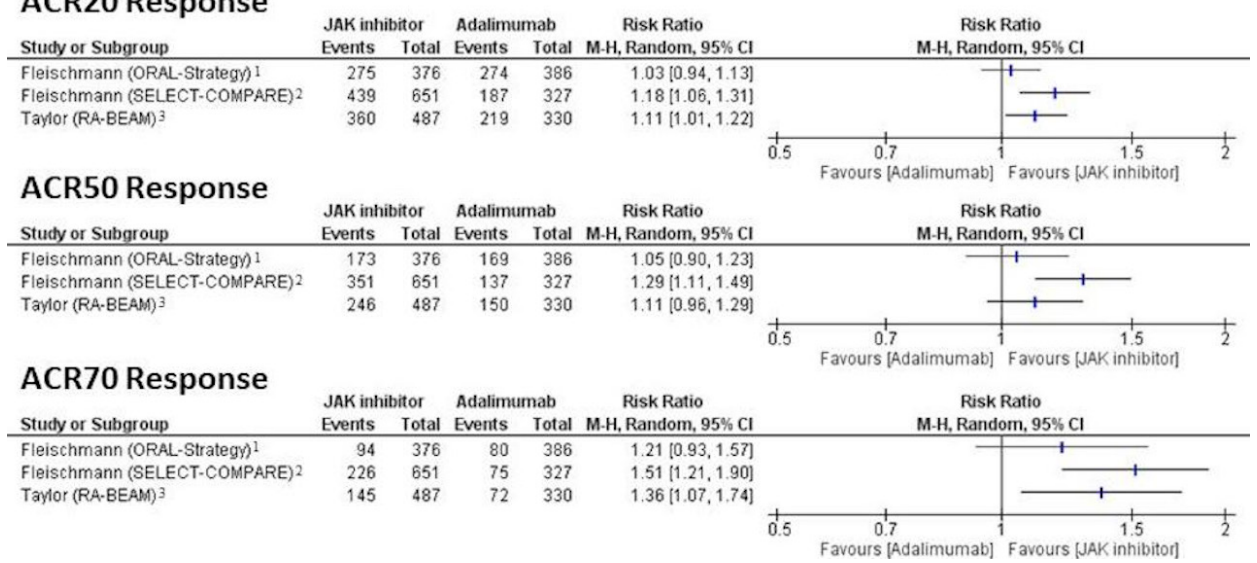

Figure 2 Forest plots showing risk ratios of ACR 20, 50 and 70 responses in trials comparing JAK inhibitors+MTX to adalimumab +MTX in MTX-IR patients. 1, tofacitinib; 2, upadacitinib; 3, baricitinib. ACR, American College of Rheumatology; IR, insufficient responder; M-H, Mantel-Haenszel; MTX, methotrexate; JAK, Janus kinase.

dose by $66 \%$ resulted in not statistically significantly different flare rates (DAS28-ESR $>3.2$ and $\triangle$ DAS28-ESR $\geq 0.6$ ) compared with treatment continuation (29\% vs $16 \%$, HR 2.52 , $95 \%$ CI 0.85 to $7.48, \mathrm{p}=0.097){ }^{122}$

A novel tapering strategy, using a biomarker, matrix metalloproteinase (MMP-3), or combined SDAI + MMP-3-guided tapering of bDMARDs in patients achieving SDAI $\leq 3.3$ and normalisation of MMP-3 showed non-inferiority at week 52 as compared with just clinically guided maintenance of SDAI $\leq 3.3$. $^{123}$ Open-label interval prolongation in patients with high ADA trough levels (defined as $>8 \mu \mathrm{g} / \mathrm{mL}$ ) did not lead to increased disease activity (using DAS28-ESR, CDAI or SDAI). ${ }^{124}$

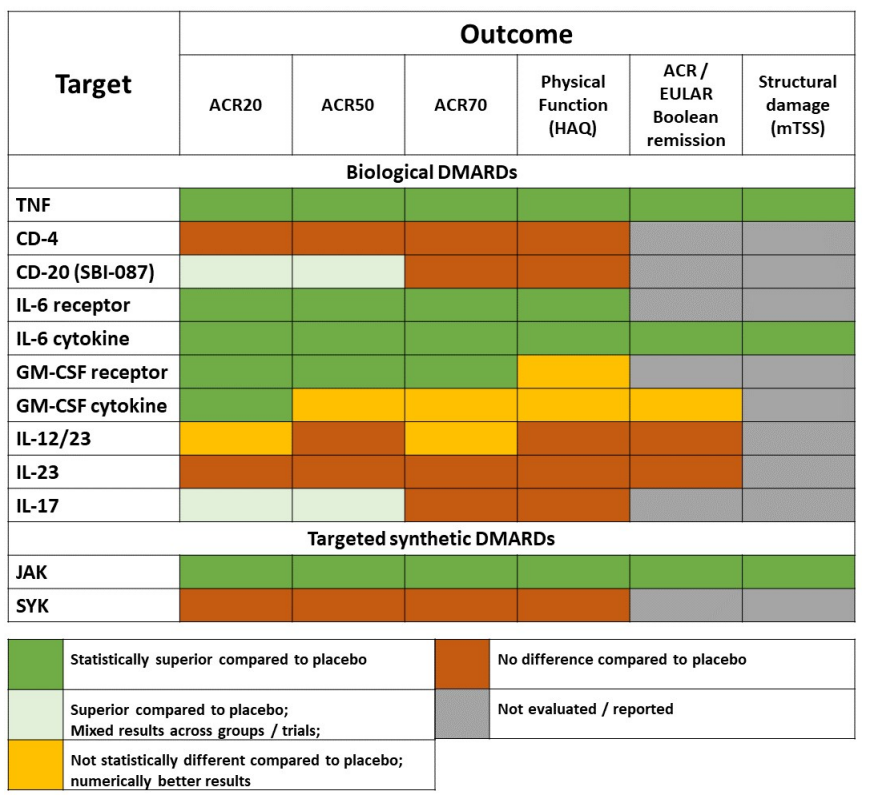

Figure 3 Efficacy of different targets of biological and targeted synthetic disease-modifying drugs compared against placebo, shown across major clinical trial outcomes of randomised controlled trials published from 2016 to 2018. ACR, American College of Rheumatology response criteria; $C D$, cluster of differentiation; DMARD, diseasemodifying antirheumatic drugs; EULAR, European League against Rheumatism; GM-CSF, colony-stimulating factor; HAQ, Health Assessment Questionnaire; IL, interleukin; JAK, Janus kinase; mTSS, modified total Sharp score; Syk, spleen tyrosine kinase; TNF, tumour necrosis factor.

\section{Tapering of tsDMARDs}

The RA-BEYOND study randomised patients from four trials of BARI at $4 \mathrm{mg}$ who had achieved stable CDAI $\leq 10$ to either continue BARI $4 \mathrm{mg}$ or reduce dose to $2 \mathrm{mg}$. While more patients who continued full dose maintained CDAI low disease activity compared with those who reduced the dose (93\% vs $83 \%, \mathrm{p}<0.001$ at 3 months; $87 \%$ vs $75 \%, \mathrm{p}<0.001$, at 6 months; $80 \%$ vs $67 \%, \mathrm{p}<0.01$ at 12 months for BARI $4 \mathrm{mg}$ continuation vs dose reduction to BARI $2 \mathrm{mg}$, respectively), a majority of patients maintained their good disease state despite dose reduction. Further, in patients being in CDAI $\leq 2.8$ at randomisation, fewer patients lost their disease activity state. Of those who flared after dose reduction, the majority $(66.7 \%)$ regained their CDAI $<10$ state within 24 weeks after dose increase to $4 \mathrm{mg}$. Thirteen of the 16 patients not regaining their CDAI $<10$ state after 24 weeks were able to do so at a subsequent time point. ${ }^{125}$

Combined bDMARDs and csDMARDs tapering and/or stopping IMPROVED, a Dutch strategy trial (high RoB) aimed at drug free remission in patients with early RA and undifferentiated arthritis. After 5 years, $15 \%-20 \%(\mathrm{p}=0.374)$ of patients could achieve drug-free remission. ${ }^{126}$

Dose reduction (by 50\%) or stopping either csDMARDs, bDMARDs or both compared with dose continuation was investigated in a study of patients achieving stable DAS28-ESR $<2.6$ for at least 6 months (high RoB). In the control group 6.5\% of patients flared, while $42 \%-77 \%$ flared after dose reduction or stopping therapy completely. ${ }^{127}$

The TARA study compared csDMARD tapering with bDMARD tapering in patients who had long-standing combination therapy and found no significant differences in the flare (defined as DAS44 >2.4 and/or SJC >1) ratio between both groups (HR 0.91; 95\% CI 0.68 to $1.22 ; \mathrm{p}=0.55$ ). ${ }^{128}$

\section{DISCUSSION}

This SLR was performed to inform the task force for the 2019 update of the EULAR recommendations for the management of RA on the efficacy of various DMARDs as presented in publications from 2016 to March 2019. These publications covered a total of 32 DMARDs.

The SLR confirmed the high efficacy of csDMARD plus GC combination therapy as well as the efficacy of TNFi, IL-6Ri, ABA 
Rheumatoid arthritis

\begin{tabular}{|c|c|c|c|c|c|c|}
\hline Study & Primary outcome & Endpoint (week) & Treatment arm & $\mathrm{N}$ & Result & $P$ value \\
\hline \multicolumn{7}{|l|}{ csDMARD tapering } \\
\hline \multirow[t]{2}{*}{ Kaeley 2016 (MUSICA) ${ }^{107}$} & \multirow[t]{2}{*}{ Mean DAS28-CRP } & \multirow[t]{2}{*}{24} & ADA $40 \mathrm{mg} \mathrm{Q2W+7.5} \mathrm{mg} \mathrm{MTX}$ & 154 & 4.12 & \multirow[t]{2}{*}{0.014} \\
\hline & & & ADA $40 \mathrm{mg}$ Q2W+20 mg MTX & 155 & 3.75 & \\
\hline \multirow[t]{2}{*}{ Keystone 2016 (CAMEO) $^{144}$} & \multirow[t]{2}{*}{$\triangle D A S 28-E S R$} & \multirow[t]{2}{*}{24} & ETN $50 \mathrm{mg}$ QW; MTX discontinuation & 98 & 0.5 & \multirow[t]{2}{*}{0.815} \\
\hline & & & ETN $50 \mathrm{mg}$ QW +MTX continuation & 107 & 0.04 & \\
\hline \multirow{2}{*}{$\begin{array}{l}\text { Pope EULAR 2017/ACR } \\
\text { 2018/2019 }\end{array}$} & \multirow[t]{2}{*}{$\triangle D A S 28-E S R$} & \multirow[t]{2}{*}{76} & CZP +csDMARD continuation & 37 & -2.1 & \multirow[t]{2}{*}{ NR } \\
\hline & & & CZP + csDMARD discontinuation & 44 & -2.1 & \\
\hline \multirow[t]{2}{*}{ Burmester ACR 2018 (SEMIRA) $)^{111}$} & \multirow[t]{2}{*}{$\triangle D A S 28-E S R$} & \multirow[t]{2}{*}{24} & $\mathrm{TCZ} \pm \mathrm{cs} D M A R D s ; \mathrm{GC}$ tapering & 131 & 0.538 & \multirow[t]{2}{*}{$<0.001$} \\
\hline & & & TCZ \pm CsDMARDs; GC continuation & 128 & -0.075 & \\
\hline \multirow[t]{2}{*}{ Pablos 2018 (JUST-ACT) 112} & \multirow[t]{2}{*}{$\triangle \mathrm{DAS} 28-E S R$ week 16 week 28} & \multirow[t]{2}{*}{28} & $\mathrm{TCZ} 8 \mathrm{mg} / \mathrm{kg}+\mathrm{MTX}$ & 82 & 0.007 & \multirow[t]{2}{*}{$95 \% \mathrm{Cl}-0.40$ to 0.27} \\
\hline & & & $\mathrm{TCZ} 8 \mathrm{mg} / \mathrm{kg}+\mathrm{PLC}$ & 82 & 0.073 & \\
\hline \multirow[t]{2}{*}{ Kremer 2018 (COMP-ACT) ${ }^{113}$} & \multirow[t]{2}{*}{$\triangle \mathrm{DAS} 28-E S R$ week 24 week 40} & \multirow[t]{2}{*}{40} & TCZ 162 mg s.c. +PLC & 147 & 0.46 & \multirow[t]{2}{*}{$95 \%$ Cl 0.045 to 0.592} \\
\hline & & & TCZ 162 mg s.c. +MTX & 147 & 0.14 & \\
\hline Edwards 2018 (ACT-TAPER) ${ }^{114}$ & Pat. Maintaining EULAR good/moderate response from & 60 & $\mathrm{TCZ} 8 \mathrm{mg} / \mathrm{kg} \mathrm{Q} 4 \mathrm{~W}+\mathrm{PBO}$ & 136 & $77 \%$ & 0.036 \\
\hline & week 24-60 & & $\mathrm{TCZ} 8 \mathrm{mg} / \mathrm{kg}$ Q4W+MTX & 136 & $65 \%$ & \\
\hline Stouten 2018 (CareRA) $)^{115} 116$ & DAS28-CRP $<2.6$ & 65 & MTX + LEF->MTX 15 mg/week & 32 & $94 \%$ & 0.031 \\
\hline & & & MTX+LEF->LEF 20 mg/day & 26 & $73 \%$ & \\
\hline bDMARD tapering & & & & & & \\
\hline $\begin{array}{l}\text { Oba 2017/Tanaka ACR } 2018 \\
(\text { RRRR) }\end{array}$ & 1-year sustained discontinuation rate of INF & 106 & $\begin{array}{l}\text { INF } 3 \mathrm{mg} / 8 \mathrm{mg} / 10 \mathrm{mg} / \mathrm{kg} \text { Q } 8 W \text { based on TNF } \\
\text { levels }\end{array}$ & 170 & $24 \%$ & 0.631 \\
\hline & & & INF standard $3 \mathrm{mg} / \mathrm{kg}$ Q8W & 167 & $21 \%$ & \\
\hline Chatzidionysiou 2016 (ADMIRE) ${ }^{142}$ & DAS28 $<2.6$ at week 28 & 28 & $\mathrm{ADA}+\mathrm{MTX}$ continuation & 16 & $94 \%$ & 0.001 \\
\hline & & & ADA discontinuation; MTX monotherapy & 16 & $33 \%$ & \\
\hline Ghiti Moghadam 2016/2018 & $\%$ of pat. DAS $28 \geq 3.2+\triangle D A S 28>0.6$ for 1 year & 52 & Stopping TNFi & 531 & $51 \%$ & $<0.001$ \\
\hline & & & Continuation of TNFi & 286 & $18 \%$ & \\
\hline Atsumi 2017 (C-OPERA) ${ }^{119}$ & $\Delta \mathrm{mTSS}$ & 104 & CZP +MTX continuation & 108 & 0.66 & 0.001 \\
\hline & & & Stopping CZP; MTX+PLC & 71 & 3.01 & \\
\hline Kaneko 2018 (SURPRISE) $)^{121}$ & TCZ free rate & 104 & stopping TCZ; MTX monotherapy & 49 & $67 \%$ & 0.001 \\
\hline & & & stopping TCZ; No DMARD & 53 & $29 \%$ & \\
\hline Weinblatt 2017 (C-EARLY) ${ }^{120}$ & DAS28-ESR $\leq 3.2$ without flares during week 52-104 & 104 & CZP 200 mg Q2W+MTX (standard) & 84 & $49 \%$ & Reference \\
\hline & & & CZP 200 mg Q4W+MTX (reduced frequency) & 126 & $53 \%$ & 0.112 \\
\hline & & & Placebo +MTX (CZP stopped) & 79 & $39 \%$ & 0.041 \\
\hline Ibrahim 2017 (OPTIRRA) ${ }^{122}$ & Flare rate $(\triangle \mathrm{DAS} 28 \geq 0.6+\mathrm{DAS} 28>3.2+\triangle \mathrm{SJC} \mathrm{OR}$ & 24 & TNFi 33\% tapering; csDMARD & 26 & $12 \%$ & 0.873 \\
\hline & $\triangle \mathrm{DAS} 2$ & & TNFi $66 \%$ tapering; csDMARD & 21 & $29 \%$ & 0.097 \\
\hline & & & Control; csDMARD continuation & 50 & $16 \%$ & Reference \\
\hline Bouman $2017(\text { DRESS) })^{145}$ & Incidence of major flare ( $\triangle \mathrm{DAS} 28-\mathrm{CRP}>1.2$ or $\triangle \mathrm{DAS} 28-$ & 144 & TNFi dose reduction extension & 115 & $17 \%$ & $3 \%, 95 \% \mathrm{Cl}-10 \%$ \\
\hline & CRP > $0.6+$ DAS28-CRP $\geq 3.2$ for $>12$ weeks) & & Usual care extension & 57 & $14 \%$ & to $15 \%$ \\
\hline l'Ami $2018^{124}$ & $\triangle D A S 28-E S R$ & 28 & ADA $40 \mathrm{mg}$ Q3W \pm MTX & 27 & -0.14 & 0.01 \\
\hline & & & $\mathrm{ADA} 40 \mathrm{mg}$ Q2W $\pm \mathrm{MTX}$ & 27 & 0.3 & \\
\hline tsDMARD tapering & & & & & & \\
\hline Takeuchi 2019 (RA-BEYOND) ${ }^{125}$ & $\mathrm{CDAl} \leq 10$ & 12 & Continued BARI $4 \mathrm{mg} \pm \mathrm{CsDMARD}$ & 281 & $93 \%$ & $<0.001$ \\
\hline & & & BARI Step-down $2 \mathrm{mg} \pm$ csDMARD & 278 & $83 \%$ & \\
\hline
\end{tabular}

$\triangle$, change from baseline; ACR, American College of Rheumatology; ADA, adalimumab; BARI, baricitinib; bDMARD, biological disease-modifying antirheumatic drug; CDAl, Clinical Disease Activity Index; CRP, C-reactive protein; cSDMARDs, conventional synthetic disease-modifying

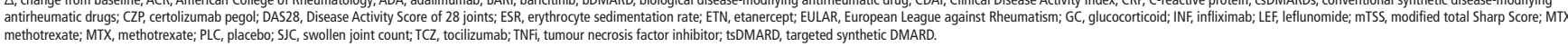

and rituximab as well as bsDMARDs in csDMARD (including MTX) IR patients. With respect to bsDMARDs, switch (including multiple switch) studies between bs and boDMARDs confirmed long-term safety and efficacy of biosimilars. Like bDMARDs, JAKi are efficacious in patients with RA. Several trials compared one bDMARD class (usually TNFi agents) with bDMARDs of other classes revealing similarity of response. Likewise, head-tohead trials between JAKi and anti-TNF did not reveal clinically important differences regarding efficacy.

In patients who failed a TNFi or other bDMARDs, tsDMARDs and also bDMARDs of the same or other classes revealed generally similar clinical efficacy ${ }^{49} 100$ or relatively small differences. ${ }^{68}$ Of interest (and part of the previous research agenda), sarilumab, an anti-IL-6R antibody, showed efficacy in patients who had an IR to TCZ, another IL-6Ri, ${ }^{67}$ and in a study published after this SLR, TNFi showed efficacy after failure of JAKi. ${ }^{129}$

A strategy trial comparing treatment aimed at clinical remission to therapy aimed at remission by MRI showed no difference in clinical outcomes, but more adverse events and more costs in the imaging group, further confirming that stringent clinical remission is a sufficient treatment target and that imaging remission not only fails to convey better efficacy, but may constitute a potentially dangerous and costly overtreatment. ${ }^{6}$

Tapering studies revealed that dose reduction of JAKi and bDMARDs is feasible and that when starting dose reduction in sustained stringent remission less patients flare when compared with start of tapering just in sustained low disease activity. ${ }^{125}$ Importantly, patients who flare can mostly $(70 \%-80 \%)$ regain their prior good response.

The results of this SLR were presented to the task force and, together with the safety SLR ${ }^{8}$ formed the basis for the update of the EULAR RA management recommendations.

\section{Author affiliations}

${ }^{1}$ Medical University of Vienna, Vienna, Austria

${ }^{2}$ Leiden University Medical Center, Leiden, The Netherlands

${ }^{3}$ NOVA Medical School, Universidade Nova de Lisboa, Lisbon, Portugal

${ }^{4}$ Hospital Cochin, Paris, France

${ }^{5}$ Amsterdam Rheumatology Center, Amsterdam, The Netherlands 
${ }^{6}$ University of Glasgow, Glasgow, UK

University Medical Center Utrecht, Utrecht, The Netherlands

${ }^{8}$ Charité - University Medicine Berlin, Berlin, Germany

${ }^{9}$ EULAR Standing Committee, Zurich, Switzerland

${ }^{10}$ Northwell Health, New York, New York, USA

Correction notice This article has been corrected since it published Online First. Table 5 formatting has been corrected and the MONARCH study line in table 3 transposed.

Contributors All authors contributed and finally approved the current manuscript.

Funding European League Against Rheumatism.

Competing interests AK: Honoraria from Bristol-Myers Squibb, Celgene, Gilead, Merck Sharp and Dohme, Novartis and Pfizer. AS: Honoraria as speaker: JSS: Grants from Abbvie, Astra-Zeneca, Janssen, Lilly, Novartis, Roche and honoraria from Abbvie, Amgen, Astra-Zeneca, Astro, BMS, Celgene, Celltrion, Chugai, Gilead, ILTOO, Janssen, Lilly, MSD, Novartis-Sandoz, Pfizer, Roche, Samsung, Sanofi, UCB. DvdH: Received consulting fees from AbbVie, Amgen, Astellas, AstraZeneca, BMS, Boehringer Ingelheim, Celgene, Daiichi, Eli-Lilly, Galapagos, Gilead, Glaxo-SmithKline, Janssen, Merck, Novartis, Pfizer, Regeneron, Roche, Sanofi, Takeda, UCB Pharma and is Director of Imaging Rheumatology bv. MD: Received research grants from and honorarium fees for his participation at advisory boards and/or symposium organised by PFIZER, UCB, ABBVIE, LILLY, NOVARTIS, BMS, ROCHE, UCB, MERCK. RvV: Research Support and Grants: BMS, GSK, Lilly, Pfizer, UCB Pharma. Consultancy, honoraria: AbbVie, AstraZeneca, Biotest, Celgene, GSK, Janssen, Lilly, Novartis, Pfizer, Servier, UCB. IM: grants from Astra Zeneca, UCB, BMS, Janssen, GSK, Compugen, Boehringer, Celgene and honoraria from Abbvie, BMS, Janssen, Novartis, UCB, Astra Zeneca, Celgene, Causeway, Lilly, Leo, Novimmune. JWB: Honoraria as speaker and for consulting: Abbvie, Lilly, MSD, Roche, Sanofi, SUNGB: Honoraria as speaker and for consulting: Abbvie, BMS, Gilead, Lilly, MSD, Pfizer, UCB, Roche, Sanofi. MdW: Over the last 2 years Stichting Tools has received fees for lectures or consultancy for contributions of Maarten de Wit from Abbvie, Celgene, Eli Lilly, Janssen-Cilag and Pfizer. LF: none. RL: Received consulting fees from AbbVie, BMS, Celgene, Eli-Lilly, Galapagos, Gilead, Glaxo-Smith-Kline, Janssen, Merck, Novartis, Pfizer, Roche, UCB and is Director of Rheumatology Consultancy bv.

Patient and public involvement statement The task force on this project involved a PPI representative (MdW), member of the EULAR Standing Committee of People with Arthritis/Rheumatism in Europe, who contributed during all task force meetings, especially to take patient perspectives into account and refine research questions.

\section{Patient consent for publication Not required.}

Provenance and peer review Not commissioned; externally peer reviewed.

Data availability statement All data relevant to the study are included in the article or uploaded as online supplementary information.

Open access This is an open access article distributed in accordance with the Creative Commons Attribution Non Commercial (CC BY-NC 4.0) license, which permits others to distribute, remix, adapt, build upon this work non-commercially, and license their derivative works on different terms, provided the original work is properly cited, appropriate credit is given, any changes made indicated, and the use is non-commercial. See: http://creativecommons.org/licenses/by-nc/4.0/.

\section{ORCID iDs}

Andreas Kerschbaumer http://orcid.org/0000-0002-6685-8873

Alexandre Sepriano http://orcid.org/0000-0003-1954-0229

Désirée van der Heijde http://orcid.org/0000-0002-5781-158X

Maarten de Wit http://orcid.org/0000-0002-8428-6354

\section{REFERENCES}

1 Nam JL, Takase-Minegishi K, Ramiro S, et al. Efficacy of biological disease-modifying antirheumatic drugs: a systematic literature review Informing the 2016 update of the EULAR recommendations for the management of rheumatoid arthritis. Ann Rheum Dis 2017;76:1113-36.

2 Chatzidionysiou K, Emamikia S, Nam J, et al. Efficacy of glucocorticoids, conventional and targeted synthetic disease-modifying antirheumatic drugs: a systematic literature review Informing the 2016 update of the EULAR recommendations for the management of rheumatoid arthritis. Ann Rheum Dis 2017:76:1102-7.

3 Ramiro S, Sepriano A, Chatzidionysiou K, et al. Safety of synthetic and biological DMARDs: a systematic literature review Informing the 2016 update of the EULAR recommendations for management of rheumatoid arthritis. Ann Rheum Dis 2017:76:1101-36.

4 Smolen JS, Burmester G-R, Combe B, et al. Head-To-Head comparison of certolizumab pegol versus adalimumab in rheumatoid arthritis: 2-year efficacy and safety results from the randomised EXXELERATE study. Lancet 2016;388:2763-74.
5 Smolen JS, Breedveld FC, Burmester GR, et al. Treating rheumatoid arthritis to target: 2014 update of the recommendations of an international Task force. Ann Rheum Dis 2016;75:3-15.

6 Møller-Bisgaard S, Hørslev-Petersen K, Ejbjerg B, et al. Effect of magnetic resonance imaging vs conventional Treat-to-Target strategies on disease activity remission and radiographic progression in rheumatoid arthritis: the IMAGINE-RA randomized clinical trial. JAMA 2019;321:461-72.

7 Smolen JS, Landewé R, Bijlsma J, et al. EULAR recommendations for the management of rheumatoid arthritis with synthetic and biological disease-modifying antirheumatic drugs: 2016 update. Ann Rheum Dis 2017:76:960-77.

8 Sepriano A, Kerschbaumer A, Smolen JS, et al. Safety of synthetic and biological DMARDs: a systematic literature review Informing the 2019 update of the EULAR recommendations for the management of rheumatoid arthritis. Ann Rheum Dis 2020;79:747-57.

9 van der Heijde D, Aletaha D, Carmona L, et al. 2014 update of the EULAR standardised operating procedures for EULAR-endorsed recommendations. Ann Rheum Dis 2015:74:8-13.

10 Verschueren P, De Cock D, Corluy L, et al. Effectiveness of methotrexate with step-down glucocorticoid remission induction (cobra slim) versus other intensive treatment strategies for early rheumatoid arthritis in a treat-to-target approach: 1 -year results of CareRA, a randomised pragmatic open-label superiority trial. Ann Rheum Dis 2017:76:511-20.

11 Stouten V, Joly J, De Cock D. Sustained effectiveness after remission induction with methotrexate and step-down glucocorticoids in patients with early rheumatoid arthritis following a treat-to-target strategy after 2 years. Arthritis and rheumatology Conference: american college of rheumatology/association of rheumatology health professionals annual scientific meeting, ACR/ARHP 2017 United states, 2017.

12 Register KA, Cannella AC, Mikuls TR. Leflunomide, sulfasalazine and hydroxychloroquine for rheumatoid arthritis: efficacious but poorly tolerated. Arthritis and rheumatology Conference: american college of rheumatology/ association of rheumatology health professionals annual scientific meeting, ACR/ ARHP 2016 United states Conference start: 20161111 Conference end: 20161116, 2016:2014-5.

13 Damjanov N, Tlustochowicz M, Aelion J, et al. Safety and efficacy of SBI-087, a subcutaneous agent for $B$ cell depletion, in patients with active rheumatoid arthritis: results from a phase II randomized, double-blind, placebo-controlled study. J Rheumatol 2016;43:2094-100.

14 Mazurov V, Denisov L, Gordeev I, et al. SAT0206 Results of the alterra clinical trial - the efficacy of the alternative dosing regimen for rituximab biosimilar in bdmards naive patients with rheumatoid arthritis. Ann Rheum Dis 2018;77:963.

15 Fleischmann R, van Adelsberg J, Lin Y, et al. Sarilumab and Nonbiologic diseasemodifying antirheumatic drugs in patients with active rheumatoid arthritis and inadequate response or intolerance to tumor necrosis factor inhibitors. Arthritis Rheumatol 2017;69:277-90.

16 Tanaka Y, Wada K, Takahashi Y. Efficacy and safety of sarilumab plus methotrexate in a phase 3 trial in Japanese patients with active rheumatoid arthritis (KAKEHASI). International journal of rheumatic diseases Conference: 20th asia pacific league of associations for rheumatology congress, APLAR 2018 Taiwan (republic of china), 2019:200.

17 Aletaha D, Bingham CO, Tanaka Y, et al. Efficacy and safety of sirukumab in patients with active rheumatoid arthritis refractory to anti-TNF therapy (SIRROUND-T): a randomised, double-blind, placebo-controlled, parallel-group, multinational, phase 3 study. Lancet 2017;389:1206-17.

18 Tanaka Y, Bingham C, Aletaha D. Sirukumab, an anti-IL-6 cytokine monoclonal antibody, significantly improves physical function and reduces morning stiffness in patients with active rheumatoid arthritis despite anti-TNF therapy: results from a global, randomized, placebo-controlled, phase 3 trial. Arthritis and rheumatology Conference: american college of rheumatology/association of rheumatology health professionals annual scientific meeting, ACR/ARHP 2016 United states Conference start: 20161111 Conference end: 20161116, 2016:2008-9.

19 Takeuchi T, Thorne C, Karpouzas G, et al. Sirukumab for rheumatoid arthritis: the phase III SIRROUND-D study. Ann Rheum Dis 2017;76:2001-8.

20 Takeuchi T, Tanaka Y, Yamanaka H, et al. Efficacy and safety of olokizumab in Asian patients with moderate-to-severe rheumatoid arthritis, previously exposed to anti-TNF therapy: results from a randomized phase II trial. Mod Rheumatol 2016;26:15-23.

21 Dorner T, Weinblatt M, Van Beneden K, et al. FRI0239 results of a phase 2B study of vobarilizumab, an anti-interleukin-6 receptor nanobody, as monotherapy in patients with moderate to severe rheumatoid arthritis. Ann Rheum Dis 2017:76:575.

22 Weinblatt M, Dorner T, Zeldin R. Results of a phase Ilb study of vobarilizumab, an anti-interleukin 6 receptor nanobody, in patients with moderate-to-severe rheumatoid arthritis despite treatment with methotrexate. Journal of rheumatology Conference: 72nd annual meeting of the canadian rheumatology association, CRA 2017 Canada, 2017:880

23 Burmester GR, McInnes IB, Kremer J, et al. A randomised phase llb study of mavrilimumab, a novel GM-CSF receptor alpha monoclonal antibody, in the treatment of rheumatoid arthritis. Ann Rheum Dis 2017;76:1020-30. 
24 Buckley C, Campos JAS, Yakushin S, et al. A phase Ilb dose-ranging study of antiGM-CSF with methotrexate treatment in patients with rheumatoid arthritis $(\mathrm{r} A)$ and an inadequate response to methotrexate. Arthritis Rheumatol 2018;70:2166-7.

25 Gupta A, Zecchin C, Fisheleva E, et al. Exposure-efficacy analysis in DMARD inadequate response rheumatoid arthritis patients treated with GSK3196165 along with methotrexate. Arthritis Rheumatol 2018;70:2799.

26 Tahir H, Deodhar A, Genovese M, et al. Secukinumab in active rheumatoid arthritis after Anti-TNF $\alpha$ therapy: a randomized, double-blind placebo-controlled phase 3 study. Rheumatol Ther 2017;4:475-88.

27 Mease PJ, Jeka S, Jaller JJ, et al. CNT06785, a fully human Antiinterleukin 17 monoclonal antibody, in patients with rheumatoid arthritis with inadequate response to methotrexate: a randomized, placebo-controlled, phase II, dose-ranging study. J Rheumatol 2018;45:22-31.

28 Dokoupilová E, Aelion J, Takeuchi T, et al. Secukinumab after anti-tumour necrosis factor- $\alpha$ therapy: a phase III study in active rheumatoid arthritis. Scand I Rheumatol 2018;47:276-81

29 van Vollenhoven RF, Keystone EC, Strand V, et al. Efficacy and safety of tregalizumab in patients with rheumatoid arthritis and an inadequate response to methotrexate: results of a phase Ilb, randomised, placebo-controlled trial. Ann Rheum Dis 2018;77:495-9.

30 Cohen S, Genovese MC, Choy E, et al. Efficacy and safety of the biosimilar ABP 501 compared with adalimumab in patients with moderate to severe rheumatoid arthritis: a randomised, double-blind, phase III equivalence study. Ann Rheum Dis 2017;76:1679-87.

31 Apsangikar P, Chaudhry S, Naik M, et al. A prospective, randomized, double-blind, comparative clinical study of efficacy and safety of a biosimilar adalimumab with innovator product in patients with active rheumatoid arthritis on a stable dose of methotrexate. Indian J Rheumatol 2018:13:84-9.

32 Cohen SB, Alonso-Ruiz A, Klimiuk PA, et al. Similar efficacy, safety and immunogenicity of adalimumab biosimilar BI 695501 and Humira reference product in patients with moderately to severely active rheumatoid arthritis: results from the phase III randomised VOLTAIRE-RA equivalence study. Ann Rheum Dis 2018;69:914-21.

33 Jamshidi A, Gharibdoost F, Vojdanian M, et al. A phase III, randomized, twoarmed, double-blind, parallel, active controlled, and non-inferiority clinical trial to compare efficacy and safety of biosimilar adalimumab (CinnoRA@) to the reference product (Humira $®)$ in patients with active rheumatoid arthritis. Arthritis Res Ther 2017;19:168.

34 Alten R, Glover J, Matsunaga N, et al. OP0021 efficacy and safety results of a phase III study comparing fkb327, an adalimumab biosimilar, with the adalimumab reference product in patients with active rheumatoid arthritis. Ann Rheum Dis 2017;76:59.

35 Genovese MC, Glover J, Greenwald M, et al. FKB327, an adalimumab biosimilar, versus the reference product: results of a randomized, phase III, double-blind study, and its open-label extension. Arthritis Res Ther 2019;21:281

36 Genovese MC, Glover J, Matsunaga N. Efficacy, safety and immunogenicity in randomized, double-blind (DB) and open-label extension (OLE) studies comparing FKB327, an adalimumab biosimilar, with the adalimumab reference product (humira; RP) in patients (PTS) with active rheumatoid arthritis (rA). Arthritis and rheumatology Conference: american college of rheumatology/association of rheumatology health professionals annual scientific meeting, ACR/ARHP 2017 United states, 2017

37 Piotr W, Sławomir J, Eva D. A randomized, double-blind, parallel-group, multicenter study to compare the efficacy, safety and immunogenicity of a proposed adalimumab Biosimilar (GP2017) with reference adalimumab in patients with moderate-to-severe active rheumatoid arthritis. 2018 ACR/ARHP Annual Meeting; Arthritis \& Rheumatology, Chicago, USA, 2018

38 Fleischmann RM, Alten R, Pileckyte $M$, et al. A comparative clinical study of PF-06410293, a candidate adalimumab biosimilar, and adalimumab reference product (Humira $($ ) in the treatment of active rheumatoid arthritis. Arthritis Res Ther 2018;20:178.

39 Weinblatt ME, Baranauskaite A, Niebrzydowski J, et al. Phase III randomized study of SB5, an adalimumab Biosimilar, versus reference adalimumab in patients with moderate-to-severe rheumatoid arthritis. Arthritis Rheumatol 2018;70:40-8.

40 Jani RH, Gupta R, Bhatia G, et al. A prospective, randomized, double-blind, multicentre, parallel-group, active controlled study to compare efficacy and safety of biosimilar adalimumab (Exemptia; ZRC-3197) and adalimumab (Humira) in patients with rheumatoid arthritis. Int J Rheum Dis 2016;19:1157-68.

41 O'Dell J, Takeuchi T, Tanaka Y, et al. OP0226 Randomized, Double-Blind Study Comparing Chs-0214 with Etanercept in Patients with Active Rheumatoid Arthritis (RA) despite Methotrexate (MTX) Therapy. Ann Rheum Dis 2016;75:143.1-143.

42 Matucci-Cerinic M, Allanore $Y$, Kavanaugh $A$, et al. Efficacy, safety and immunogenicity of GP2015, an etanercept biosimilar, compared with the reference etanercept in patients with moderate-to-severe rheumatoid arthritis: 24-week results from the comparative phase III, randomised, double-blind EQUIRA study. RMD Open 2018;4:e000757

43 Bae S-C, Kim J, Choe J-Y, et al. A phase III, multicentre, randomised, double-blind, active-controlled, parallel-group trial comparing safety and efficacy of HD203, with innovator etanercept, in combination with methotrexate, in patients with rheumatoid arthritis: the HERA study. Ann Rheum Dis 2017:76:65-71.

44 Matsuno H, Tomomitsu M, Hagino A, et al. Phase III, multicentre, double-blind, randomised, parallel-group study to evaluate the similarities between LBEC0101 and etanercept reference product in terms of efficacy and safety in patients with active rheumatoid arthritis inadequately responding to methotrexate. Ann Rheum Dis 2018;77:488-94

45 Lila A, Denisov L, Plaksina T. Efficacy and safety of BCD-055 (infliximab biosimilar) in rheumatoid arthritis. Results of BCD-055-3/lira phase 3 clinical study. Annals of the rheumatic diseases Conference: annual european congress of rheumatology, EULAR 2018 Netherlands, 2018:316-7.

46 Lila AM, Mazurov VI, Denisov LN, et al. A phase III study of BCD-055 compared with innovator infliximab in patients with active rheumatoid arthritis: 54-week results from the LIRA study. Rheumatol Int 2019;39:1537-46.

47 Yoo DH, Racewicz A, Brzezicki J, et al. A phase III randomized study to evaluate the efficacy and safety of CT-P13 compared with reference infliximab in patients with active rheumatoid arthritis: 54-week results from the PLANETRA study. Arthritis Res Ther 2016;18:82.

48 Matsuno H, Matsubara T. A randomized double-blind parallel-group phase III study to compare the efficacy and safety of $\mathrm{NI}-071$ and infliximab reference product in Japanese patients with active rheumatoid arthritis refractory to methotrexate. Modern Rheumatology 2018;05:1-26.

49 Cohen SB, Alten $\mathrm{R}$, Kameda $\mathrm{H}$, et al. A randomized controlled trial comparing PF$06438179 / G P 1111$ (an infliximab biosimilar) and infliximab reference product for treatment of moderate to severe active rheumatoid arthritis despite methotrexate therapy. Arthritis Res Ther 2018:20:155.

50 Choe J-Y, Prodanovic N, Niebrzydowski J, et al. A randomised, double-blind, phase III study comparing Sb2, an infliximab biosimilar, to the infliximab reference product remicade in patients with moderate to severe rheumatoid arthritis despite methotrexate therapy. Ann Rheum Dis 2017;76:58-64.

51 Smolen JS, Choe J-Y, Prodanovic N, et al. Comparing biosimilar Sb2 with reference infliximab after 54 weeks of a double-blind trial: clinical, structural and safety results. Rheumatology 2017:56:1771-9.

52 Nasonov E, Mazurov V, Plaksina T. Interchangeability of innovator rituximab and its biosimilar: results from international controlled comparative 1-year study in patients with active rheumatoid arthritis. Arthritis and rheumatology Conference: american college of rheumatology/association of rheumatology health professionals annual scientific meeting, ACR/ARHP 2016 United states Conference start: 20161111 Conference end: 20161116, 2016:2046-7.

53 Park W, Božić-Majstorović L, Milakovic D, et al. Comparison of biosimilar CT-P10 and innovator rituximab in patients with rheumatoid arthritis: a randomized controlled phase 3 trial. MAbs 2018;10:934-43.

54 Haridas V, Katta R, Nalawade A. Double-blind randomized parallel arm study of 3 anti CD20 monoclonal antibodies in patients with moderate to severe, sero-positive rheumatoid arthritis inadequately responding to metho-trexate based therapy. Efficacy safety \& immunogenicity results. Journal of rheumatology Conference: 73rd annual meeting of the canadian rheumatology association, CRA 2018 Canada, 2018:1052.

55 Smolen JS, Cohen SB, Tony H-P, et al. A randomised, double-blind trial to demonstrate bioequivalence of GP2013 and reference rituximab combined with methotrexate in patients with active rheumatoid arthritis. Ann Rheum Dis 2017;76:1598-602

56 Weinblatt ME, Baranauskaite A, Dokoupilova E, et al. Switching from reference adalimumab to SB5 (adalimumab Biosimilar) in patients with rheumatoid arthritis: Fifty-Two-Week phase III randomized study results. Arthritis Rheumato 2018;70:832-40

57 O'Dell J, Kivitz A, Takeuchi T, et al. SAT0162 switching from etanercept to CHS-0214: a one year, randomized, double-blind study in patients with rheumatoid arthritis. Ann Rheum Dis 2017:76:831.

58 Song YW, Matsuno H, Park MC, et al. Efficacy and safety of switching from etanercept product to LBEC0101 (etanercept biosimilar) compared with continuing LBEC0101 in patients with rheumatoid arthritis. Annals of the rheumatic diseases conference: annual European Congress of rheumatology, EULAR 2018 Netherlands 2018:77:1389-90.

59 Park M-C, Matsuno H, Kim J, et al. Long-Term efficacy, safety and immunogenicity in patients with rheumatoid arthritis continuing on an etanercept biosimilar (LBEC0101) or switching from reference etanercept to LBEC0101: an open-label extension of a phase III multicentre, randomised, double-blind, parallel-group study. Arthritis Res Ther 2019;21:122

60 Smolen JS, Choe J-Y, Prodanovic N, et al. Safety, immunogenicity and efficacy after switching from reference infliximab to biosimilar Sb2 compared with continuing reference infliximab and Sb2 in patients with rheumatoid arthritis: results of a randomised, double-blind, phase III transition study. Ann Rheum Dis 2018;77:234-40.

61 Jørgensen KK, Olsen IC, Goll GL, et al. Switching from originator infliximab to biosimilar CT-P13 compared with maintained treatment with originator infliximab (NOR-SWITCH): a 52-week, randomised, double-blind, non-inferiority trial. Lancet 2017;389:2304-16. 
62 Porter D, van Melckebeke J, Dale J, et al. Tumour necrosis factor inhibition versus rituximab for patients with rheumatoid arthritis who require biological treatment (orbit): an open-label, randomised controlled, non-inferiority, trial. Lancet 2016:388:239-47.

63 Burmester GR, Lin Y, Patel R, et al. Efficacy and safety of sarilumab monotherapy versus adalimumab monotherapy for the treatment of patients with active rheumatoid arthritis (monarch): a randomised, double-blind, parallel-group phase III trial. Ann Rheum Dis 2017;76:840-7.

64 Weinblatt ME, McInnes IB, Kremer JM, et al. A randomized phase Ilb study of Mavrilimumab and golimumab in rheumatoid arthritis. Arthritis Rheumatol 2018;70:49-59.

65 Genovese MC, Weinblatt ME, Aelion JA, et al. ABT-122, a bispecific dual variable domain immunoglobulin targeting tumor necrosis factor and interleukin-17A, in patients with rheumatoid arthritis with an inadequate response to methotrexate: a randomized, double-blind study. Arthritis Rheumatol 2018;70:1710-20.

66 Taylor PC, Schiff MH, Wang Q, et al. Efficacy and safety of monotherapy with sirukumab compared with adalimumab monotherapy in biologic-naïve patients with active rheumatoid arthritis (SIRROUND-H): a randomised, double-blind, parallelgroup, multinational, 52-week, phase 3 study. Ann Rheum Dis 2018;77:658-66.

67 Verschueren P, Emery P, Van Hoogstraten $\mathrm{H}$, et al. Efficacy of sarilumab in patients with rheumatoid arthritis with and without previous response to tocilizumab. Annals of the rheumatic diseases conference: annual European Congress of rheumatology, EULAR 2018 Netherlands 2018;77:327-8.

68 Gottenberg J-E, Brocq O, Perdriger A, et al. Non-TNF-Targeted biologic vs a second anti-TNF drug to treat rheumatoid arthritis in patients with insufficient response to a first anti-TNF drug: a randomized clinical trial. JAMA 2016:316:1172-80.

69 Emery P, Bingham CO, Burmester GR, et al. Certolizumab pegol in combination with dose-optimised methotrexate in DMARD-naïve patients with early, active rheumatoid arthritis with poor prognostic factors: 1-year results from C-EARLY, a randomised, double-blind, placebo-controlled phase III study. Ann Rheum Dis 2017;76:96-104

70 Emery P, Tanaka Y, Bykerk VP. Efficacy and safety of abatacept in combination with MTX in early, MTX-Naïve, Anti-Citrullinated protein Antibody-Positive patients with RA: primary and 1-year results from a phase IIIB study. 2018 ACR/ARHP Annual Meeting Chicago, USA; 2018 2018: Arthritis Rheumatol, 2018.

71 Stamm TA, Machold KP, Aletaha D, et al. Induction of sustained remission in early inflammatory arthritis with the combination of infliximab plus methotrexate: the DINORA trial. Arthritis Res Ther 2018;20.

72 Burmester GR, Rigby WF, van Vollenhoven RF, et al. Tocilizumab combination therapy or monotherapy or methotrexate monotherapy in methotrexate-naive patients with early rheumatoid arthritis: 2-year clinical and radiographic results from the randomised, placebo-controlled function trial. Ann Rheum Dis 2017;76:1279-84.

73 Fleischmann RM, Damjanov NS, Kivitz AJ, et al. A randomized, double-blind, placebocontrolled, twelve-week, dose-ranging study of decernotinib, an oral selective JAK-3 inhibitor, as monotherapy in patients with active rheumatoid arthritis. Arthritis Rheumatol 2015:67:334-43.

74 Genovese MC, Yang F, Østergaard M, et al. Efficacy of VX-509 (decernotinib) in combination with a disease-modifying antirheumatic drug in patients with rheumatoid arthritis: clinical and MRI findings. Ann Rheum Dis 2016;75:1979-83.

75 Genovese MC, van Vollenhoven RF, Pacheco-Tena C, et al. VX-509 (Decernotinib), an oral selective JAK-3 inhibitor, in combination with methotrexate in patients with rheumatoid arthritis. Arthritis Rheumatol 2016:68:46-55.

76 Takeuchi T, Tanaka Y, Iwasaki M, et al. Efficacy and safety of the oral Janus kinase inhibitor peficitinib (ASP015K) monotherapy in patients with moderate to severe rheumatoid arthritis in Japan: a 12-week, randomised, double-blind, placebocontrolled phase llb study. Ann Rheum Dis 2016;75:1057-64.

77 Genovese MC, Greenwald M, Codding C, et al. Peficitinib, a JAK inhibitor, in combination with limited conventional synthetic disease-modifying antirheumatic drugs in the treatment of moderate-to-severe rheumatoid arthritis. Arthritis Rheumatol 2017;69:932-42.

78 Kivitz AJ, Gutierrez-Ureña SR, Poiley J, et al. Peficitinib, a JAK inhibitor, in the treatment of moderate-to-severe rheumatoid arthritis in patients with an inadequate response to methotrexate. Arthritis Rheumatol 2017;69:709-19.

79 Tanaka Y, Takeuchi T, Tanaka S. Efficacy and safety of the novel oral Janus kinase (JAK) inhibitor, Peficitinib (ASP015K), in a phase 3, double-blind, placebo-controlled randomized study of patients with RA who had an inadequate response to Dmards. 2018 ACR/ARHP Annual Meeting Chicago, USA; 2018: Arthritis \& Rheumatology, 2018.

80 Takeuchi T, Tanaka Y, Tanaka S. Efficacy and safety of the novel oral Janus kinase (JAK) inhibitor, peficitinib (ASP015K), in a phase 3, double-blind, placebo-controlled, randomized study of patients with $R A$ who had an inadequate response to methotrexate. 2018 ACR/ARHP annual meeting Chicago, USA; 2018, 2018

81 Takeuchi T, Tanaka Y, Tanaka S, et al. Efficacy and safety of peficitinib (ASP015K) in patients with rheumatoid arthritis and an inadequate response to methotrexate: results of a phase III randomised, double-blind, placebo-controlled trial (RAJ4) in Japan. Ann Rheum Dis 2019;78:1305-19.

82 Tanaka Y, Takeuchi T, Tanaka S, et al. Efficacy and safety of peficitinib (ASP015K) in patients with rheumatoid arthritis and an inadequate response to conventional
DMARDs: a randomised, double-blind, placebo-controlled phase III trial (RAJ3). Ann Rheum Dis 2019;78:1320-32.

83 Westhovens R, Taylor PC, Alten R, et al. Filgotinib (GLPG0634/GS-6034), an oral JAK1 selective inhibitor, is effective in combination with methotrexate (MTX) in patients with active rheumatoid arthritis and insufficient response to MTX: results from a randomised, dose-finding study (Darwin 1). Ann Rheum Dis 2017;76:998-1008

84 Kivitz A, Mehta D, Matzkies F. GS-9876, a novel, highly selective, Syk inhibitor in patients with active rheumatoid arthritis: safety, tolerability and efficacy results of a phase 2 study. 2018 ACR/ARHP Annual Meeting Chicago, USA: Arthritis \& Rheumatology, 2018.

85 Dougados M, van der Heijde D, Chen Y-C, et al. Baricitinib in patients with inadequate response or intolerance to conventional synthetic DMARDs: results from the RA-BUILD study. Ann Rheum Dis 2017;76:88-95.

86 Genovese M, Van Der Heijde D, Dougados M. Baricitinib inhibits radiographic progression of structural joint damage at 1 year in patients with rheumatoid arthritis $(\mathrm{rA})$ and an inadequate response to conventional synthetic disease-modifying antirheumatic drugs (CSDMARDS). Internal medicine journal Conference: new zealand rheumatology association and australian rheumatology association with the rheumatology health professionals association joint annual scientific meeting New zealand, 2017:32.

$87 \mathrm{Hu}$ J, Bao C, Li X. Efficacy and safety of baricitinib in MTX-IR patients with rheumatoid arthritis: 52 week results from a phase 3 study (RA-balance). Annals of the rheumatic diseases conference: annual European Congress of rheumatology, EULAR 2018 Netherlands, 2018:969-70.

88 Yue Y, Hu J, Bao C. Patient-Reported outcomes from a phase 3 study (RA-BALANCE) of baricitinib versus placebo in rheumatoid arthritis. International journal of rheumatic diseases Conference: 20th asia pacific league of associations for rheumatology congress, APLAR 2018 Taiwan, 2018:40.

89 Fleischmann R, Schiff M, van der Heijde D, et al. Baricitinib, methotrexate, o combination in patients with rheumatoid arthritis and no or limited prior diseasemodifying antirheumatic drug treatment. Arthritis Rheumatol 2017:69:506-17.

90 Schiff M, Takeuchi T, Fleischmann R, et al. Patient-Reported outcomes of baricitinib in patients with rheumatoid arthritis and no or limited prior disease-modifying antirheumatic drug treatment. Arthritis Res Ther 2017;19:208.

91 van Vollenhoven R, Takeuchi T, Pangan AL. A phase 3, randomized, controlled trial comparing Upadacitinib monotherapy to MTX monotherapy in MTX-Naïve patients with active rheumatoid arthritis. ACR Meeting Abstracts. 2018 ACR/ARHP Annual Meeting Chicago, USA, 2018.

92 Smolen J, Cohen S, Emery P. Upadacitinib as monotherapy: a phase 3 randomised controlled double-blind study in patients with active rheumatoid arthritis and inadequate response to methotrexate. Annals of the rheumatic diseases conference: annual European Congress of rheumatology, EULAR 2018 Netherlands, 2018:67-8.

93 Smolen J, Cohen S, Emery P. Upadacitinib as monotherapy: a phase 3 randomized controlled double-blind study in patients with active rheumatoid arthritis and inadequate response to methotrexate. 2018 ACR/ARHP Annual Meeting Chicago, USA, 2018

94 Strand V, Buch M, Tundia N. Upadacitinib monotherapy improves patient-reported outcomes in patients with rheumatoid arthritis and inadequate response to methotrexate. 2018 ACR/ARHP Annual Meeting Chicago, USA, 2018.

95 Tanaka Y, Takeuchi T, Yamaoka K. A phase 2B/3 randomised, placebo-controlled, double-blind study of upadacitinib, a selective JAK1 inhibitor, in Japanese patients with active rheumatoid arthritis and inadequate response to conventional synthetic DMARDs. Annals of the rheumatic diseases conference: annual European Congress of rheumatology, EULAR 2018 Netherlands, 2018:991-2.

96 Burmester GR, Kremer JM, Van den Bosch F, et al. Safety and efficacy of upadacitinib in patients with rheumatoid arthritis and inadequate response to conventional synthetic disease-modifying anti-rheumatic drugs (SELECT-NEXT): a randomised, double-blind, placebo-controlled phase 3 trial. Lancet 2018;391:2503-12.

97 Strand V, Pope J, Tundia N. Upadacitinib improves patient-reported outcomes in patients with rheumatoid arthritis and inadequate response to conventional synthetic disease-modifying anti-rheumatic drugs: results from selectnext. Annals of the rheumatic diseases conference: annual European Congress of rheumatology, EULAR 2018 Netherlands, 2018:989-90.

98 Smolen JS, Pangan AL, Emery P, et al. Upadacitinib as monotherapy in patients with active rheumatoid arthritis and inadequate response to methotrexate (SELECTMONOTHERAPY): a randomised, placebo-controlled, double-blind phase 3 study. Lancet 2019:393:2303-11.

99 Genovese MC, Fleischmann R, Combe B, et al. Safety and efficacy of upadacitinib in patients with active rheumatoid arthritis refractory to biologic disease-modifying anti-rheumatic drugs (SELECT-BEYOND): a double-blind, randomised controlled phase 3 trial. Lancet 2018:391:2513-24. 0623

100 Strand V, Schiff M, Tundia N. Patient reported outcomes of upadacitinib: results from biologic inadequate responders (select beyond phase III trial). Annals of the rheumatic diseases Conference: annual european congress of rheumatology, EULAR 2018 Netherlands, 2018:990.

101 Taylor PC, Keystone EC, van der Heijde D, et al. Baricitinib versus placebo or adalimumab in rheumatoid arthritis. N Engl J Med 2017;376:652-62. 
102 Keystone EC, Taylor PC, Tanaka Y, et al. Patient-Reported outcomes from a phase 3 study of baricitinib versus placebo or adalimumab in rheumatoid arthritis: secondary analyses from the RA-BEAM study. Ann Rheum Dis 2017;76:1853-61.

103 Strand V, Mysler E, Moots RJ. Tofacitinib with and without methotrexate versus adalimumab with methotrexate for the treatment of rheumatoid arthritis: patientreported outcomes from a phase $3 \mathrm{~b} / 4$ randomised trial. Annals of the rheumatic diseases conference: annual European Congress of rheumatology, EULAR 2018 Netherlands, 2018:990-1.

104 Fleischmann R, Mysler E, Hall S, et al. Efficacy and safety of tofacitinib monotherapy, tofacitinib with methotrexate, and adalimumab with methotrexate in patients with rheumatoid arthritis (oral strategy): a phase 3b/4, double-blind, head-to-head, randomised controlled trial. Lancet 2017;390:457-68.

105 Fleischmann R, Pangan AL, Mysler E. A phase 3, randomized, double-blind study comparing upadacitinib to placebo and to adalimumab, in patients with active rheumatoid arthritis with inadequate response to methotrexate. 2018 ACR/ARHP annual meeting Chicago, USA; 2018, 2018

106 Fleischmann R, Pangan AL, Song I-H, et al. Upadacitinib versus placebo or adalimumab in patients with rheumatoid arthritis and an inadequate response to methotrexate: results of a phase III, double-blind, randomized controlled trial. Arthritis Rheumatol 2019;71:1788-800

107 Kaeley GS, Evangelisto AM, Nishio MJ, et al. Methotrexate dosage reduction upon adalimumab initiation: clinical and ultrasonographic outcomes from the randomized noninferiority MUSICA trial. J Rheumato/ 2016;43:1480-9.

108 Pope J, Rampakakis E, Grant E. DMARD withdrawal in RA patients achieving therapeutic response with certolizumab pegol combined with DMARDs: interim results from a Canadian observational randomized study. Annals of the rheumatic diseases Conference: annual european congress of rheumatology, EULAR 2017 Spain, 2017:58.

109 Pope JE, Rampakakis E, Vaillancourt J. DMARD Withdrawal in RA Patients Achieving Therapeutic Response with Certolizumab Pegol Combined with Dmards: Results from a Canadian Randomized Study - ACR Meeting Abstracts. 2018 ACR/ARHP Annual Meeting Chicago, USA, 2018

110 Pope J, Rampakakis E, Vaillancourt J, et al. An open-label randomized controlled trial of DMARD withdrawal in RA patients achieving therapeutic response with certolizumab pegol combined with DMARDs. Rheumatology 2019;9.

111 Burmester GR, Buttgereit F, Bernasconi C. A randomized controlled 24-week trial evaluating the safety and efficacy of blinded tapering versus continuation of longterm prednisone ( $5 \mathrm{mg} /$ day) in patients with rheumatoid arthritis who achieved low disease activity or remission on tocilizumab. 2018 ACR/ARHP annual meeting Chicago, USA, 2018

112 Pablos JL, Navarro F, Blanco FJ, et al. Efficacy of tocilizumab monotherapy after response to combined tocilizumab and methotrexate in patients with rheumatoid arthritis: the randomised JUST-ACT study. Clin Exp Rheumatol 2019;37:437-44.

113 Kremer JM, Rigby W, Singer NG, et al. Sustained response following discontinuation of methotrexate in patients with rheumatoid arthritis treated with subcutaneous tocilizumab: results from a randomized, controlled trial. Arthritis Rheumatol 2018;70:1200-8

114 Edwards CJ, Östör AJK, Naisbett-Groet B, et al. Tapering versus steady-state methotrexate in combination with tocilizumab for rheumatoid arthritis: a randomized, double-blind trial. Rheumatology 2018:57:84-91.

115 Stouten V, Michiels S, Belba A. Effectiveness of a randomized step-down to methotrexate or leflunomide maintenance therapy in patients with low disease activity, 40 weeks after starting combined methotrexate-leflunomide remission induction therapy in early rheumatoid arthritis: results from the carera trial. Annals of the rheumatic diseases conference: annual European Congress of rheumatology, EULAR 2018 Netherlands, 2018:967-8.

116 Stouten V, Westhovens R, Pazmino $\mathrm{S}$, et al. Effectiveness of different combinations of DMARDs and glucocorticoid bridging in early rheumatoid arthritis: two-year results of CareRA. Rheumatology 2019;58:2284-94.

117 Ghiti Moghadam M, Vonkeman HE, Ten Klooster PM, et al. Stopping tumor necrosis factor inhibitor treatment in patients with established rheumatoid arthritis in remission or with stable low disease activity: a pragmatic multicenter, open-label randomized controlled trial. Arthritis Rheumatol 2016;68:1810-7.

118 Ghiti Moghadam M, ten Klooster PM, Vonkeman HE, et al. Impact of stopping tumor necrosis factor inhibitors on rheumatoid arthritis patients' burden of disease. Arthritis Care Res 2018;70:516-24

119 Atsumi T, Tanaka Y, Yamamoto K, et al. Clinical benefit of 1-year certolizumab pegol (CZP) add-on therapy to methotrexate treatment in patients with early rheumatoid arthritis was observed following CZP discontinuation: 2-year results of the C-OPERA study, a phase III randomised trial. Ann Rheum Dis 2017;76:1348-56

120 Weinblatt ME, Bingham CO, Burmester G-R, et al. A phase III study evaluating continuation, tapering, and withdrawal of Certolizumab pegol after one year of therapy in patients with early rheumatoid arthritis. Arthritis Rheumatol 2017;69:1937-48

121 Kaneko Y, Kato M, Tanaka Y, et al. Tocilizumab discontinuation after attaining remission in patients with rheumatoid arthritis who were treated with tocilizumab alone or in combination with methotrexate: results from a prospective randomised controlled study (the second year of the surprise study). Ann Rheum Dis 2018:77:1268-75.

122 Ibrahim F, Lorente-Cánovas B, Doré CJ, et al. Optimizing treatment with tumour necrosis factor inhibitors in rheumatoid arthritis-a proof of principle and exploratory trial: is dose tapering practical in good responders? Rheumatology 2017;56:2004-14.

123 Urata Y, Abe S, Devers B. A novel dose reduction therapy using biological diseasemodifying anti-rheumatic drugs to target matrix metalloproteinase 3 normalization together with a simplified disease activity index $<3.3$ yields effects non-inferior to standard care in rheumatoid arthritis with regards maintaining remission. Annals of the rheumatic diseases Conference: annual european congress of rheumatology of the european league against rheumatism, EULAR 2016 United kingdom Conference start: 20160608 Conference end: 20160611, 2016:204-5.

124 I'Ami MJ, Krieckaert CL, Nurmohamed MT, et al. Successful reduction of overexposure in patients with rheumatoid arthritis with high serum adalimumab concentrations: an open-label, non-inferiority, randomised clinical trial. Ann Rheum Dis 2018;77:484-7.

125 Takeuchi T, Genovese MC, Haraoui B, et al. Dose reduction of baricitinib in patients with rheumatoid arthritis achieving sustained disease control: results of a prospective study. Ann Rheum Dis 2019;78:171-8.

126 Akdemir G, Heimans L, Bergstra SA, et al. Clinical and radiological outcomes of 5year drug-free remission-steered treatment in patients with early arthritis: improved study. Ann Rheum Dis 2018;77:111-8.

127 El Miedany Y, El Gaafary M, Youssef S, et al. Optimizing therapy in inflammatory arthritis: prediction of relapse after tapering or stopping treatment for rheumatoid arthritis patients achieving clinical and radiological remission. Clin Rheumatol 2016;35:2915-23

128 Van Mulligen E, Weel A, Kuijper TM. Gradual tapering TNF blockers versus conventional synthetic dmards in patients with rheumatoid arthritis in sustained remission: first year results of the randomised controlled tara-study. Annals of the rheumatic diseases Conference: annual european congress of rheumatology, EULAR 2018 Netherlands, 2018:107.

129 Fleischmann RM, Genovese MC, Enejosa JV, et al. Safety and effectiveness of upadacitinib or adalimumab plus methotrexate in patients with rheumatoid arthritis over 48 weeks with switch to alternate therapy in patients with insufficient response. Ann Rheum Dis 2019;78:1454-62.

130 Shin K, Baek HJ, Kang YM, et al. Efficacy and safety of add-on tacrolimus versus leflunomide in rheumatoid arthritis patients with inadequate response to methotrexate. Int J Rheum Dis 2019:22:1115-22.

131 Stamp LK, O’Donnell JL, Frampton C, et al. A pilot randomized controlled doubleblind trial of high- versus low-dose Weekly folic acid in people with rheumatoid arthritis receiving methotrexate. J Clin Rheumatol 2019;25:284-7.

132 Bi L, Li Y, He L, et al. Efficacy and safety of certolizumab pegol in combination with methotrexate in methotrexate-inadequate Responder Chinese patients with active rheumatoid arthritis: 24-week results from a randomised, double-blind, placebocontrolled phase 3 study. Clin Exp Rheumatol 2019;37:227-34.

133 Smolen JS, Agarwal SK, Ilivanova E, et al. A randomised phase II study evaluating the efficacy and safety of subcutaneously administered ustekinumab and guselkumab in patients with active rheumatoid arthritis despite treatment with methotrexate. Ann Rheum Dis 2017:76:831-9.

134 Takeuchi T, Yamanaka H, Harigai M, et al. Sirukumab in rheumatoid arthritis refractory to sulfasalazine or methotrexate: a randomized phase 3 safety and efficacy study in Japanese patients. Arthritis Res Ther 2018;20:42

135 Matsubara T, Inoue H, Nakajima T, et al. Abatacept in combination with methotrexate in Japanese biologic-naive patients with active rheumatoid arthritis: a randomised placebo-controlled phase IV study. RMD Open 2018;4:e000813.

136 Tanaka Y, Wada K, Takahashi Y, et al. Sarilumab plus methotrexate in patients with active rheumatoid arthritis and inadequate response to methotrexate: results of a randomized, placebo-controlled phase III trial in Japan. Arthritis Res Ther 2019;21:79.

137 Strand V, Gossec L, Proudfoot CWJ, et al. Patient-Reported outcomes from a randomized phase III trial of sarilumab monotherapy versus adalimumab monotherapy in patients with rheumatoid arthritis. Arthritis Res Ther 2018;20:129.

138 Blanco FJ, Möricke R, Dokoupilova E, et al. Secukinumab in active rheumatoid arthritis: a phase III randomized, double-blind, active Comparator- and placebocontrolled study. Arthritis Rheumatol 2017:69:1144-53.

139 Burmester GR, Rigby WF, van Vollenhoven RF, et al. Tocilizumab in early progressive rheumatoid arthritis: function, a randomised controlled trial. Ann Rheum Dis 2016;75:1081-91

140 Oba K, Horie N, Sato N, et al. Remission induction by raising the dose of remicade in RA (RRRR) study: rationale and study protocol for a randomized controlled trial comparing for sustained clinical remission after discontinuation of infliximab in patients with rheumatoid arthritis. Contemp Clin Trials Commun 2017:8:49-54.

141 Tanaka Y, Oba K, Koike T, et al. Sustained clinical remission after discontinuation of infliximab with a raising dose strategy in patients with rheumatoid arthritis (RRRR study): a randomized controlled trial. Arthritis and Rheumatology 2018;70:3170-2 
142 Chatzidionysiou K, Turesson C, Teleman A, et al. A multicentre, randomised, controlled, open-label pilot study on the feasibility of discontinuation of adalimumab in established patients with rheumatoid arthritis in stable clinical remission. $R M D$ Open 2016;2:e000133.

143 Emery P, Burmester GR, Bykerk VP, et al. Re-treatment with abatacept plus methotrexate for disease flare after complete treatment withdrawal in patients with early rheumatoid arthritis: 2-year results from the avert study. RMD Open 2019;5:e000840

144 Keystone EC, Pope JE, Thorne JC, et al. Two-Year radiographic and clinical outcomes from the Canadian methotrexate and etanercept outcome study in patients with rheumatoid arthritis. Rheumatology 2016;55:327-34.

145 Bouman $\mathrm{CA}$, van Herwaarden $\mathrm{N}$, van den Hoogen $\mathrm{FH}$, et al. Long-term outcomes after disease activity-guided dose reduction of TNF inhibition in rheumatoid arthritis: 3-year data of the DRESS study - a randomised controlled pragmatic non-inferiority strategy trial. Ann Rheum Dis 2017;76:1716-22.

146 Mueller R, Spaeth M, von Restorff C, et al. Superiority of a Treat-to-Target strategy over conventional treatment with fixed csDMARD and corticosteroids: a multicenter randomized controlled trial in RA patients with an inadequate response to conventional synthetic DMARDs, and new therapy with Certolizumab pegol. J Clin Med 2019;8:302

147 Kavanaugh A, Kremer J, Ponce L, et al. Filgotinib (GLPG0634/GS-6034), an oral selective JAK1 inhibitor, is effective as monotherapy in patients with active rheumatoid arthritis: results from a randomised, dose-finding study (Darwin 2). Ann Rheum Dis 2017;76:1009-19.
148 Genovese M, Westhovens R, Meuleners L, et al. Effect of filgotinib, a selective JAK 1 inhibitor, with and without methotrexate in patients with rheumatoid arthritis: patient-reported outcomes. Arthritis Res Ther 2018;20:57.

149 Tanaka Y, Sugiyama N, Toyoizumi S, et al. Modified- versus immediate-release tofacitinib in Japanese rheumatoid arthritis patients: a randomized, phase III, noninferiority study. Rheumatology 2019;58:70-9.

150 van der Heijde D, Strand V, Tanaka Y, et al. Tofacitinib in combination with methotrexate in patients with rheumatoid arthritis: clinical efficacy, radiographic and safety outcomes from the 24-month phase 3 oral scan study. Arthritis Rheumatol 2019;22:22.

151 Smolen JS, Kremer JM, Gaich CL, et al. Patient-Reported outcomes from a randomised phase III study of baricitinib in patients with rheumatoid arthritis and an inadequate response to biological agents (RA-BEACON). Ann Rheum Dis 2017;76:694-700.

152 van der Heijde D, Dougados M, Chen Y-C, et al. Effects of baricitinib on radiographic progression of structural joint damage at 1 year in patients with rheumatoid arthritis and an inadequate response to conventional synthetic disease-modifying antirheumatic drugs. RMD Open 2018;4:e000662.

153 Jaworski J, Matucci-Cerinic M, Schulze-Koops H, et al. Switch from reference etanercept to SDZ ETn, an etanercept biosimilar, does not impact efficacy, safety, and immunogenicity of etanercept in patients with moderate-to-severe rheumatoid arthritis: 48-week results from the phase III, randomized, double-blind EQUIRA study. Arthritis Res Ther 2019;21:130. 